\title{
Parallel lives? Ethnic segregation in schools and neighbourhoods
}

\author{
Simon Burgess, Deborah Wilson and Ruth Lupton
}

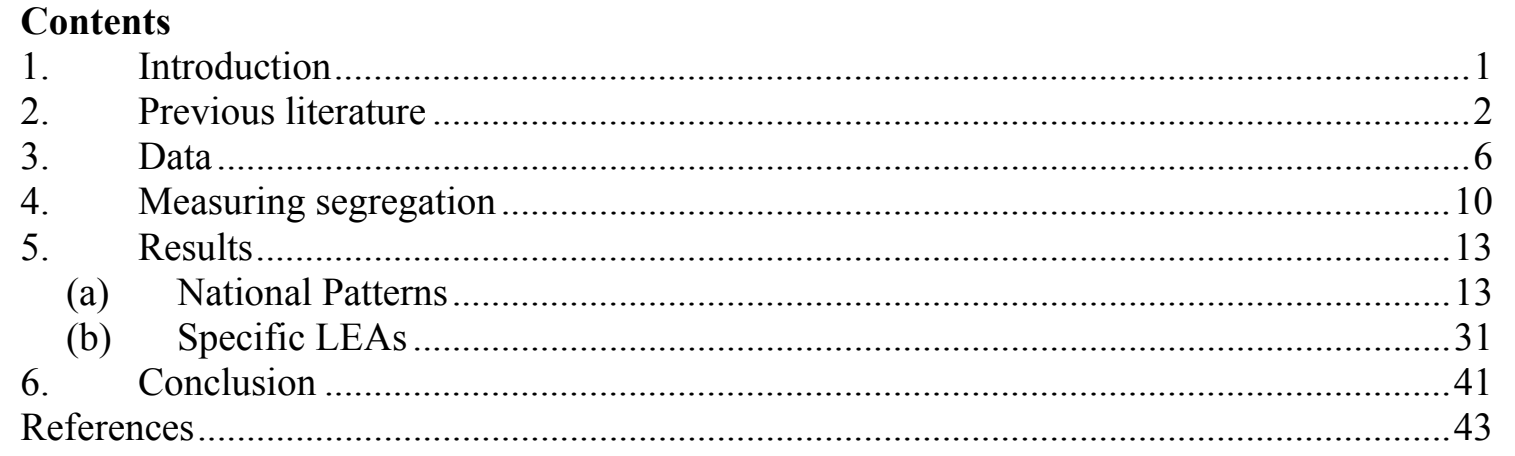

CASEpaper 101

June 2005
Centre for Analysis of Social Exclusion London School of Economics Houghton Street London WC2A $2 \mathrm{AE}$

CASE enquiries - tel: 02079556679 


\section{Centre for Analysis of Social Exclusion}

The ESRC Research Centre for Analysis of Social Exclusion (CASE) was established in October 1997 with funding from the Economic and Social Research Council. It is located within the Suntory and Toyota International Centres for Economics and Related Disciplines (STICERD) at the London School of Economics and Political Science, and benefits from support from STICERD. It is directed by Howard Glennerster, John Hills, Kathleen Kiernan, Julian Le Grand, Anne Power and Carol Propper.

Our Discussion Paper series is available free of charge. We also produce summaries of our research in CASEbriefs, and reports from various conferences and activities in CASEreports. To subscribe to the CASEpaper series, or for further information on the work of the Centre and our seminar series, please contact the Centre Administrator, Jane Dickson, on:

Telephone: $\quad$ UK+20 79556679

Fax: $\quad$ UK+20 $\quad$ je556951

Email: $\quad$ j.dickson@1se.ac.uk

Web site: http://sticerd.lse.ac.uk/case

(C) Simon Burgess

Deborah Wilson

Ruth Lupton

All rights reserved. Short sections of text, not to exceed two paragraphs, may be quoted without explicit permission provided that full credit, including $(\odot$ notice, is given to the source. 


\title{
Editorial Note and Acknowledgements
}

Simon Burgess is Professor of Economics in the Department of Economics and Director of the Centre for Market and Public Organisation (CMPO) at the University of Bristol, and an associate of CASE. Deborah Wilson is a Senior Research Officer at the CMPO. Ruth Lupton is Lecturer in Sociology of Education, Institute of Education, and an associate of CASE.

Thanks to the Leverhulme Trust for partly funding this work through the Centre for Market and Public Organisation, and to the Department for Education and Skills for supplying the schools data. Thanks also to Adele Atkinson and Brendon McConnell for compiling the datasets, and to delegates at a Neighbourhoods conference in Bristol and four anonymous referees for comments on an earlier draft. The views expressed in this paper are our own.

\begin{abstract}
We provide evidence on the extent of ethnic segregation experienced by children across secondary schools and neighbourhoods (wards). Using 2001 Schools Census and Population Census data we employ the indices of dissimilarity and isolation and compare patterns of segregation across nine ethnic groups, and across Local Education Authorities in England. Looking at both schools and neighbourhoods, we find high levels of segregation for the different groups, along with considerable variation across England. We find consistently higher segregation for South Asian pupils than for Black pupils. For most ethnic groups children are more segregated at school than in their neighbourhood. We analyse the relative degree of segregation and show that high population density is associated with high relative school segregation.
\end{abstract}

JEL codes: J7, J16, J42

Keywords: Education, sorting

Address for Correspondence:

CMPO

Department of Economics

University of Bristol

12 Priory Road

Bristol BS8 1TN

Tel: $\quad+44$ (0)117954 8436 (Burgess)

Tel: $\quad+44$ (0)117928 7795 (Wilson)

Fax: +44 (0)117954 6997

Simon.Burgess@bristol.ac.uk

D.Wilson@bristol.ac.uk 


\section{Introduction}

It is a common saying that individuals' attitudes are strongly influenced by their school days. The peer groups that children play with, talk to and work with are important factors moulding their perspectives on society. In this regard, the degree of ethnic group social integration is a major issue of political concern. The degree of ethnic segregation in schools 'may affect such things as the level and distribution of academic achievement in the population, racial attitudes, subsequent social and economic outcomes of students, and patterns of residential integration' (Clotfelter, 2001, p.199). But how segregated are England's schools? Aren't most schools mostly made up of White children? How does school segregation compare to residential segregation? And how do the answers to these questions vary across different ethnic groups, and different areas of the country? Surprisingly, there is very little contemporary evidence on this issue for England. The aim of this paper is to fill this gap, as a first step to further analysis of the impact of such segregation on educational outcomes.

We combine data from the 2001 Annual Schools Census and the 2001 Census of Population to measure the levels of segregation experienced by secondary school age children at school and in their neighbourhood (ward). We employ the two most widely used indices of segregation: one measuring the (un)evenness of the distribution of minority groups, and the other capturing the degree of isolation or contact between the minority and majority groups. The latter index directly addresses the degree to which children from different ethnic groups come into contact. We compare the patterns of these results across nine ethnic groups, and across Local Education Authorities (LEAs) in England. ${ }^{1} \mathrm{We}$ find that levels of segregation are typically high, but vary considerably across the country. We also find important differences between ethnic groups and between school and neighbourhood segregation. On average school segregation is greater than the segregation of the same group in the surrounding neighbourhood. Regression analysis shows that the ratio of school to neighbourhood segregation increases with the population density of the area. One interpretation of this is that greater density allows greater choice of school and that this in turn is associated with greater segregation.

The rest of the paper is structured as follows. Section 2 briefly describes the related literature. Section 3 details our datasets, and section 4 the methods we use to measure segregation. In section 5 we present our results, first looking at

$1 \quad$ We discuss the role played by LEAs in Section 4 below. 
the national picture, before focussing on a few selected areas. Section 6 concludes.

\section{Previous literature}

There is a large literature on how to measure segregation, which primarily focuses on residential segregation across urban areal units. Massey and Denton (1988) distinguish five dimensions of residential segregation: evenness, exposure, concentration, centralisation and clustering. Each is conceptually distinct, picking up different aspects of the phenomenon. Concentration, centralisation and clustering are all explicitly spatial in nature and as such we cannot address them using our schools data. Here, therefore, we focus on evenness and exposure.

Evenness refers to the differential distribution of two social groups in a city (Massey and Denton, 1988). An uneven distribution of a minority group across areal units results in segregation of that group. Following Duncan and Duncan (1955), the most widely used measure of evenness is the index of dissimilarity, $D$. Exposure refers to the degree of potential contact between members of different social groups within areal units. The most widely used measure of exposure is the isolation index, $I$ (see Massey and Denton (1988) for a discussion of the relative merits of alternative measures of evenness and exposure). So we pick up on two dimensions of segregation by using both $D$ and $I$. While evenness and exposure are conceptually distinct, Massey and Denton find that they are closely correlated empirically.

The issue of ethnic residential segregation has long been a concern, particularly in the United States. Cutler, Glaeser and Vigdor (1999) provide consistent, long term measures of ethnic segregation in American cities from 1890 to 1990. They conclude that, first, segregation rose until 1970 and then 'modestly' declined; second, that segregation across cities is extremely persistent and positively related to city size. Borjas (1997) distinguishes two issues the literature tries to address: the measurement of the degree of segregation in specific geographical areas (Bean and Tienda, 1987; Massey and Denton, 1989; McKinney and Schnare, 1989) and the implications of this (Case and Katz, 1991; Crane, 1991; Cutler and Glaeser, 1997). The general conclusion from the latter is that neighbourhood effects do have a significant impact on outcomes.

In the UK context, Peach (1996) uses 1991 census data to measure the degree of segregation in British cities and compare this to the levels found in the US. He finds that the proportions individual ethnic minorities form of local area (ward and enumeration district) populations are 'nowhere near as high as that formed 
regularly by the African American population in the US' (Peach, 1996, p.221). $\mathrm{He}$ does find differences between ethnic minorities in Britain, however: Caribbean average levels of residential segregation are much lower than those for Bangladeshis or Pakistanis and generally below those for Indians. These patterns are related to the length of time that each group has been established in the country - all groups have dispersed gradually over time. They also reflect between-group differences in patterns of immigration and dispersal that are linked to economic opportunity, access to housing and racial hostility as well as family and community support (Simpson, 2004). In other words, segregation needs to be seen in a historical context, not as recent nor as driven solely by a desire for self-segregation on the part of minority groups.

Previous research on school segregation in the UK has focused primarily on income segregation, and in particular whether the introduction of the education quasi-market has increased or decreased such segregation (Glennerster, 1991; Burgess et al., 2004). Eligibility for free school meals is generally employed in such studies as an indicator of low income. Gorard and Fitz (1998a, 1998b) use a variant of the isolation index on Welsh and English data and conclude in both cases that income segregation has decreased since the quasi-market was introduced as part of the Education Reform Act of $1988 .^{2}$

There is more evidence on both the levels of and changes in the degree of ethnic segregation in schools from the US. This has been an issue since the Brown vs. Board of Education decision in 1954 introduced mandatory desegregation policies such as 'bussing' in certain school districts (Johnston, 1984; Woodward, 2002), the aim being to 'dismantle the system of apartheid schools' with a view to improving educational outcomes for minority ethnic students (Rivkin, 2000, p.333). Levels of ethnic segregation decreased until the 1980s, but recent evidence from the Civil Rights Project at Harvard University suggests that this trend was reversed through the 1990s, partly due to changes in, or relaxations of, desegregation law made through more recent Supreme Court decisions. Using 2000/2001 data, Frankenberg et al. (2003) find that Whites are the most segregated group in US public schools: the average White student attends a school which is 80 per cent White. Latinos are the most segregated minority group; Asians the most integrated. ${ }^{3}$ So-called apartheid schools (those whose pupils are 99-100 per cent non-White) have re-emerged: in 2000/2001 they educated one-sixth of Black and one-ninth of Latino students. The trend towards resegregation is not only an urban phenomenon: while the

2 See also Gorard (2000) and Gorard, Taylor and Fitz (2003).

3 Minority ethnic group categorisations as reported in Frankenberg et al. (2003). 
largest city school systems are almost exclusively non-White, there are also resegregation patterns emerging in suburban areas.

Residential segregation is undoubtedly a multi-faceted issue (Blalock, 1967). As Massey and Denton (1988) state: ethnic segregation arises from a 'complex interplay of many different social and economic processes'; it does not simply follow income or class contours, nor is it likely to be fully explained by competitive, impersonal market-based theories: social interactions and networks are also potentially important explanatory factors (Arrow, 1998). Moreover, segregation patterns may partly be driven by sorting based on factors correlated with race as oppose to race preferences themselves (Schelling, 1971). Bayer et al. (2003) provide evidence that different non-race factors (such as income and education) drive the segregation of different minority ethnic groups to differing extents.

So both choices and constraints may be important in determining residential location (Dorsett, 1998; Johnston et al. 2004). School segregation can be viewed as adding a further layer onto an already complex picture, given that it incorporates the influence of both the geographical location of pupils and their families and the attendance policies employed by school districts (Rivkin, 1994). Rivkin attempts to separate these two influences using US data from 1968 to 1988 . He concludes that the high level of ethnic segregation in US schools is primarily due to continued high levels of residential segregation: Reardon et al. (2000) and Clotfelter (1998) concur with this conclusion. Segregated housing patterns are a significant barrier to the potential success of any school district's integrative action. In the UK, a particular question is the impact the education quasi-market and the emphasis on parental choice has had on the degree of ethnic segregation in schools (Tomlinson, 2001).

The impact of ethnic segregation in schools may be felt across various spheres. As Clotfelter (2001, p.199) states: 'racial contact in schools may affect such things as the level and distribution of academic achievement in the population, racial attitudes, subsequent social and economic outcomes of students, and patterns of residential integration'. The Equality of Educational Opportunity Report in the US (Coleman et al., 1966) provided evidence that racial isolation harms academic achievement (Rivkin, 2000). The racial achievement gap in the US declined in the 1970s and 1980s (the 'desegregation era') but began to grow again in the 1990s (Frankenberg et al., 2003). Rivkin (2000) investigates the impact of school desegregation on academic attainment and earnings. He finds that raising the quality of education in schools that Black students attend has more impact on their outcomes than reallocating students across schools. Shortterm outcomes of schooling such as test scores may provide too narrow a focus when we consider the impact of segregation on pupils' education, however 
(Frankenberg et al., 2003). They identify three areas of student outcomes strengthened by an integrated school environment: 'enhanced learning, higher educational and occupational aspirations, and positive social interaction among members of different racial and ethnic backgrounds' (Frankenberg et al., 2003, p. 12; see also references therein).

The relative attainment of different minority ethnic groups relative to their White peers is also an issue in the UK. Gillborn and Mirza (2000) present a review of the evidence on the impact of race, class and gender on educational attainment and conclude that inequalities of attainment at GCSE place AfricanCaribbean, Pakistani and Bangladeshi students at a disadvantage with regard to further training and the labour market. ${ }^{4}$ A further review undertaken on behalf of the Runnymede Trust (Amin et al., 1997) state that the underachievement of African-Caribbean pupils is a particular concern: their attainment levels are half those of their White peers. Cline et al. (2002) specifically looked at the experience of minority ethnic pupils in 'mainly White' schools, i.e. those in which only $4-6 \%$ of pupils were from minority ethnic backgrounds. They conclude that such schools do not adequately prepare their students for adult life in a culturally and ethnically diverse society. Bhattacharyya et al. (2003) identify schools that most help minority ethnic children as having strong leadership and systems, a culture of achievement, intensive support for pupils and close links with parents.

More generally, the impact of school segregation on social interaction between different ethnic groups has certainly been identified in the UK as cause for concern. In a previous paper (Burgess and Wilson, 2003) we identify areas of particularly high segregation for South Asian pupils and find that these coincide almost exactly with the locations of severe public disorder in 2001 (in Bradford, Oldham and Burnley). This suggests that either school segregation plays a direct role in the underlying causes of discontent (as suggested by the Cantle Report on the riots: Cantle, 2001), or is related through a correlation with housing segregation. Both the Cantle report and the Ouseley report on the aftermath of the riots in Bradford highlight the importance of schools, among other factors. Ouseley sets out the dysfunctional consequences of school segregation. He notes the role of both all-White and all-Muslim schools in preventing social and racial integration (Ouseley, 2001, p.1), and reports the victimisation of minorities in largely mono-cultural schools, whether Asian, White or Black. The report also proposes as its first recommendation that the ignorance of other groups deriving from polarisation and self-segregation must be ended. More recently, the Office of the Deputy Prime Minister (ODPM) Select Committee

4 GCSE examinations are taken in England by pupils aged 16 at the end of compulsory schooling. 
held an inquiry into the issue of social cohesion, and specifically the progress that had been made in these towns since 2001 (House of Commons, 2004). The fact that many schools do not reflect the range of cultural groups in the locality was highlighted by the Committee as one factor which hindered the promotion of social cohesion (paragraph 49).

Several LEAs have undertaken a range of initiatives aimed at increasing interaction between students who attend highly segregated schools (often reflecting in part, of course, highly segregated residential patterns in these areas). ${ }^{5}$ A good example of such a scheme is the Schools Linking Project in Oldham, which by June 2003 involved 38 primary schools (Haddock, 2003). The aim of the project is 'To bring together young people from diverse ethnic and social backgrounds in order to break down some of the barriers which exist between different communities in Oldham' (Haddock, 2003, p.4). Pupils from different schools are involved in a wide range of activities, from theatre, music and art, to cultural visits to different mosques and churches. There is also a joint schools council and a staff training program. In areas which have a long history of segregated housing, these types of schemes are one way in which the extent to which different communities live 'parallel lives' (Cantle, 2001) can be reduced, and thus the detrimental impact of such segregation minimised.

\section{Data}

To measure ethnic segregation across schools, we use data from the Annual Schools Census (ASC). Returning this data is a mandatory requirement for schools. We focus on state maintained secondary schools in England in 2001 (the pupils are aged from 11 to 16 or 18). We use data on the ethnic composition of schools. This is reported by the school, based on information provided by parents at point of admission. Data on ethnic identity for each individual pupil is now available in PLASC (Pupil Level Annual Schools Census) and is the subject of ongoing research by the authors and colleages.

One important question in this field is the definitions of ethnicity available. Often, these are rather aggregated, while other evidence and casual empiricism suggests that there is a diversity of experience within such broad ethnic groups. ${ }^{6}$

5 Other initiatives aimed at promoting social cohesion in schools in segregated areas have focused on the role played by the school curriculum (House of Commons 2004).

6 For example, incidence of low income is very different: in 2000/01, 60\% of Pakistanis and Bangladeshis lived in low-income households, compared to $25 \%$ of Indians, $19 \%$ of Black Caribbeans and 17\% of Whites. 
The ASC data available to us give the number of pupils in each school classified as being of:

$\begin{array}{ll}> & \text { Black, Caribbean heritage } \\ > & \text { Black, African heritage } \\ > & \text { Indian, other heritage } \\ > & \text { Pakistani ethnic origin } \\ > & \text { Bangladeshi ethnic origin } \\ > & \text { Chinese ethnic origin } \\ >\quad \text { Any other minority ethnic origin } \\ >\quad \text { White ethnic origin } \\ \text { For comparison with more aggregated }\end{array}$

For comparison with more aggregated groups in other work, we also report results for the created groups 'Black' combining the three Black groups, and 'South Asian' combining Indian, Pakistani and Bangladeshi.

We make a small number of sample selection decisions. We omit independent schools, special schools and other academic centres such as hospital schools and detention centres. We also drop schools that could not be matched using school number. We omit the nine schools with missing ethnicity data, and we drop all schools from LEAs with very few schools: the Isles of Scilly (1 school), the Isle of Wight (5), Rutland (3), Kensington and Chelsea (4), and Hartlepool (5). This leaves us with data on 3060 schools in 144 LEAs.

To measure ethnic segregation across neighbourhoods we use data on ethnicity at the electoral ward level, taken from the 2001 Census of Population (CP). Ethnicity is also largely parent-reported in the Population Census, as in the ASC. While the CP provides more disaggregated ethnic categories, we have aggregated these into the ASC categories listed above, in order to ensure comparability between our measures of segregation across schools and neighbourhoods. ${ }^{7}$ The nearest match age of group we can choose is 10-17 years, whereas the ASC data includes all at secondary school - 11-18 years.

Since we want to compare segregation across schools and neighbourhoods we need to check how comparable the data on ethnic composition is in the two sources. Table 1 describes the ethnic composition of the secondary school-age population in England in 2001, according to the ASC (column 1) and the CP

Footnote 6 cont. (Source: http://www.statistics.gov.uk/cci/nugget.asp?id=269 using HBAI and Family Resources Survey). See also Dorsett (1998).

7 Note that we omit the two LAs which contain only one ward: City of London and Isles of Scilly. This leaves us with data from 7927 electoral wards. 
(column 2). ${ }^{8}$ Clearly the majority overall are White, with about $1.2 \%$ of both Black Caribbean heritage and Black African heritage; $2.5 \%$ of Indian ethnic origin and Pakistani ethnic origin; $1 \%$ Bangladeshi and $0.5 \%$ Chinese. The table shows a reasonably good correspondence between the two datasets for most ethnic groups, but rather poorer for 'Black, other heritage', 'Chinese ethnic origin', and 'other minority ethnic origin'. The reasons for the discrepancies between the two datasets for these groups are not clear., ${ }^{9,10}$

Table 1: Composition of the school-age population, England 2001

\begin{tabular}{lccc}
\hline \hline & $\begin{array}{c}\text { Secondary school } \\
\text { population } \\
(\mathbf{1 1 - 1 8 )} \mathbf{( \% )}\end{array}$ & $\begin{array}{c}\text { School age population } \\
\mathbf{( 1 0 - 1 7 )}(\%)\end{array}$ & $\begin{array}{c}\text { Population } \\
\text { (all ages) (\%) }\end{array}$ \\
\hline Black, Caribbean heritage & 1.455 & 1.222 & 1.142 \\
Black, African heritage & 1.227 & 1.248 & 0.969 \\
Black, other heritage & 0.816 & 0.337 & 0.194 \\
Indian ethnic origin & 2.712 & 2.594 & 2.093 \\
Pakistani ethnic origin & 2.488 & 2.302 & 1.438 \\
Bangladeshi ethnic origin & 0.973 & 0.989 & 0.560 \\
Chinese ethnic origin & 0.399 & 0.539 & 0.449 \\
Other minority ethnic origin & 2.537 & 3.659 & 2.230 \\
& & & 4.091 \\
South Asian & 6.173 & 5.885 & 2.305 \\
Black & 3.498 & 2.807 & 90.925 \\
White ethnic origin & 87.393 & 87.109 & \\
\hline \hline
\end{tabular}

Source of Data: 2001 Annual Schools Census; 2001 Population Census

Tables 2 and 3 examine in more detail the distribution of ethnic composition of wards and schools. Most wards and most schools are overwhelmingly White, with medians of $95 \%$ and $97 \%$ respectively. The median values for all other groups is less than $1 \%$ (except 'other minority ethnic group' across wards).

$8 \quad$ We also include data from the $\mathrm{CP}$ on the ethnic composition of the whole population (column 3). The comparison show that ethnic minorities form a slightly higher proportion of children than of the population as a whole.

9

Our checks suggest that it was not due to mis-aggregation of the 'mixed race' categories, included for the first time in the 2001 Census of Population.

10 We have carried out further comparability checks across the two datasets, the results of which are reported in an earlier version of this paper available at http://www.bris.ac.uk/Depts/CMPO/workingpapers/wp94.pdf. 
Even in the 'most Black' or 'most South Asian' schools and wards - that is, those in the top 5\% with 'Black' (respectively 'South Asian') students - that aggregate ethnic group is still in the minority.

Table 2: Ethnic composition of wards (ages 10-17) (\%), England 2001

\begin{tabular}{lccccccc}
\hline \hline & Mean & p50 & p75 & p90 & p95 & p99 & Max \\
\hline Black, Caribbean heritage & 1.222 & 0 & 0.732 & 3.44 & 7.432 & 16.355 & 27.123 \\
Black, African heritage & 1.248 & 0 & 0.584 & 3.003 & 8.006 & 19.843 & 41.159 \\
Black, other heritage & 0.337 & 0 & 0.256 & 1.006 & 2.067 & 4.738 & 7.692 \\
Indian ethnic origin & 2.594 & 0.534 & 1.881 & 5.843 & 12.929 & 37.434 & 82.107 \\
Pakistani ethnic origin & 2.302 & 0 & 0.994 & 4.855 & 12.451 & 42.506 & 74.468 \\
Bangladeshi ethnic origin & 0.989 & 0 & 0.467 & 1.604 & 3.817 & 16.915 & 87.061 \\
Chinese ethnic origin & 0.539 & 0.254 & 0.704 & 1.402 & 2.08 & 4.336 & 28.696 \\
Other minority ethnic origin & 3.659 & 2.333 & 4.785 & 9.318 & 11.899 & 16.203 & 39.773 \\
& & & & & & & \\
South Asian & 5.885 & 1.075 & 4.172 & 16.726 & 34.182 & 67.952 & 89.002 \\
Black & 2.807 & 0.316 & 1.544 & 7.724 & 17.986 & 37.624 & 62.012 \\
White ethnic origin & 87.109 & 95.582 & 98.02 & 99.085 & 99.595 & 100 & 100 \\
\hline \hline
\end{tabular}

Weighted by number of individuals aged 10-17

The $\mathrm{p} 50$ etc values refer to the 50th percentile of the relevant distribution

Source of Data: 2001 Population Census

Comparison of Tables 2 and 3 suggest that the data on ethnic composition from the two sources is generally comparable across the distribution as well as at the mean. Overall, we feel confident in comparing the two datasets, with qualifications for Black pupils with 'other' heritage, Chinese pupils and pupils of other minority ethnic origin. 
Table 3: Ethnic composition of schools (ages 11-18) (\%), England 2001

\begin{tabular}{lccccccc}
\hline \hline & Mean & $\mathbf{p 5 0}$ & $\mathbf{p 7 5}$ & $\mathbf{p 9 0}$ & $\mathbf{p 9 5}$ & $\mathbf{p 9 9}$ & Max \\
\hline Black, Caribbean heritage & 1.455 & 0.132 & 0.768 & 3.846 & 8.584 & 19.948 & 72.787 \\
Black, African heritage & 1.227 & 0.118 & 0.451 & 2.851 & 7.637 & 21.091 & 49.579 \\
Black, other heritage & 0.816 & 0.152 & 0.56 & 2.159 & 3.938 & 10.728 & 30.297 \\
Indian ethnic origin & 2.712 & 0.406 & 1.598 & 6.004 & 14.374 & 39.32 & 98.084 \\
Pakistani ethnic origin & 2.488 & 0.139 & 0.976 & 5.832 & 13.619 & 43.913 & 88.088 \\
Bangladeshi ethnic origin & 0.973 & 0 & 0.331 & 1.207 & 3.495 & 18.486 & 98.61 \\
Chinese ethnic origin & 0.399 & 0.224 & 0.499 & 0.965 & 1.399 & 2.957 & 35.294 \\
Other minority ethnic origin & 2.537 & 0.623 & 2.064 & 6.751 & 11.321 & 22.89 & 99.919 \\
& & & & & & & \\
South Asian & 6.173 & 0.847 & 4.298 & 17.711 & 33.333 & 75.31 & 99.251 \\
Black & 3.498 & 0.534 & 1.986 & 9.818 & 19.872 & 43.078 & 86.885 \\
White ethnic origin & 87.393 & 97.105 & 98.911 & 99.47 & 99.697 & 100 & 100 \\
\hline \hline
\end{tabular}

Weighted by secondary school pupil numbers

The p50 etc values refer to the 50th percentile of the relevant distribution

Source of Data: 2001 Annual Schools Census

\section{Measuring segregation}

Segregation is a characteristic of an aggregate of units, in our case schools and neighbourhoods (or wards). We ask whether students from different ethnic backgrounds are distributed evenly or not over the schools (neighbourhoods) in a grouping of schools (neighbourhoods). There are different possibilities available to group these units. Administrative geographies such as local education authorities (LEAs) are widely used in other studies, and are important for two reasons. First, they are policy-making bodies and so might be expected to have an impact (and some responsibility). Second, they occupy the same borders as local authorities (LAs), ${ }^{11}$ which enables us to compare levels of school and neighbourhood segregation across the relevant units within the same geographical area. An alternative geography is based on parents' decisions on where to live, and therefore what distance their children should travel to school. These are equivalent to over-lapping catchment districts around schools. In this study, we use LEAs and postpone study of catchment areas to later work.

11 Some LEAs comprise more than one LA, but in these cases the latter can be exactly aggregated into the former; the other LEAs are equivalent to LAs. 
Following the literature, we focus on two main measures of segregation. ${ }^{12}$ These are a measure of dissimilarity (evenness), and a measure of isolation (exposure). Massey and Denton (1988) discuss these and other measures in detail, setting out their advantages and disadvantages. No single measure captures all aspects of segregation, and all have some statistical shortcomings. Nevertheless, these two are the mostly widely used. The dissimilarity index was discussed in detail by Duncan and Duncan (1955), and used for example more recently by Cutler, Glaeser and Vidgor (1999) for the US. The formula for the index of dissimilarity, $D$, is given by the following, taking the example of Black Caribbean heritage:

$$
D=1 / 2 \sum_{i=1}^{N}\left|\frac{\mathrm{BAC}_{i}}{\mathrm{BAC}_{\text {total }}}-\frac{(\mathrm{ALL}-\mathrm{BAC})_{i}}{(\mathrm{ALL}-\mathrm{BAC})_{\text {total }}}\right|
$$

where $\mathrm{BAC}_{i}$ is the number of students of Black Caribbean heritage in school $\mathrm{i}$, $\mathrm{ALL}_{i}$ is the total students in school $i, \mathrm{BAC}_{\text {total }}$ is the total number of students of Black Caribbean heritage in the LEA, (ALL - BAC) $)_{i}$ is the number of students not of Black Caribbean heritage in school $i,(\mathrm{ALL}-\mathrm{BAC})_{\text {total }}$ is the number of students not of Black Caribbean heritage in the LEA, and $\mathrm{N}$ is the number of schools in the LEA. Note that our calculation therefore measures the segregation of each minority relative to all other groups combined. We additionally compare each group against each other pairwise, individually, using $D$ and taking London as the aggregate spatial unit. The dissimilarity index ranges from 0 to 1 and, continuing the above example, has the interpretation of the fraction of students of Black Caribbean heritage in the LEA that need to be moved to different schools (wards) in order to make each school (ward) have the same composition in terms of that group. Cutler, Glaeser and Vidgor (1999) quote Massey and Denton (1993) suggesting that values of $0-0.3$ are considered to be low, $0.3-0.6$ moderate, and 0.6 and above high.

We also compute an isolation index. Continuing the example of students of Black Caribbean heritage, this is essentially the percentage of the school belonging to this group, averaged over all students in that group. In other words, it is interpretable as the average probability of meeting someone with the same ethnicity as you. This links closely with the concept of school children from different ethnic groups living 'parallel lives' - Massey and Denton (1988, p.287) note that 'Rather than measuring segregation as departure from some abstract idea of 'evenness', exposure [or isolation] indices attempt to measure

12 Johnston, Wilson and Burgess (2004) employs an alternative, graphical technique of concentration profiles to investigate patterns of ethnic segregation across schools. 
the experience of segregation as felt by the average minority or majority member' (emphasis in original). ${ }^{13}$ The core expression for this is:

$$
I=\sum_{i=1}^{N} \frac{\mathrm{BAC}_{i}}{\mathrm{BAC}_{\text {total }}} \cdot \frac{\mathrm{BAC}_{i}}{\mathrm{ALL}_{i}}
$$

This needs to be adjusted to take account of areas with small representations of the ethnic group in question. We follow Cutler, Glaeser and Vidgor (1999) in adopting the following form (see their discussion for more details):

$$
I=\frac{\sum_{i=1}^{N} \frac{B A C_{i}}{B A C_{\text {total }}} \cdot \frac{B A C_{i}}{A L L_{i}}-\left(\frac{B A C_{\text {total }}}{A L L_{\text {total }}}\right)}{\min \left(\left(\frac{B A C_{\text {total }}}{\min \left(A L L_{i}\right)}\right), 1\right)-\left(\frac{B A C_{\text {total }}}{A L L_{\text {total }}}\right)}
$$

where $\min \left(A L L_{i}\right)$ is the size of the smallest school. This ranges from 0 to 1 , with a value of 0.3 being considered high.

One technical issue we need to consider is that LEAs vary considerably in terms of the number of units (schools or wards) that we compute segregation over. For example, the 10th and 90th percentiles of the distribution of schools per LEA are 9 and 42, and for wards are 17 and 160. This is important since the number of units used matters when measuring segregation, and may distort comparisons of LEAs. However, the number of units per head of population varies much less, and this is the crucial issue. This makes sense, since the numbers of people in a ward or in a school are fairly constant and governed by electoral regulations and school design. In fact the coefficient of variation for pupils per school across LEAs is 0.14 , compared to 0.80 for the number of schools across LEAs.

A second technical issue arises from the comparison of the two different bases for segregation. There are about twice as many wards per LEA as there are schools (means of 53.1 and 21.2). This again matters for comparing segregation. As Massey and Denton (1988, p.299) argue 'smaller areal units generally yield higher indices of segregation because they are more homogeneous'. We do not have a straightforward comparison here as wards are areas and schools are points, though with some generally ill-defined catchment area. Nevertheless, all else equal, we would expect the smaller wards to produce higher segregation indices simply as an artefact of the different geographies.

13 Of course, the experience and feeling of isolation in this index is imputed rather than measured directly. 
We calculate (1) and (3) for each ethnic group defined above, first across schools then across wards. We do this at the national level, that is defining the aggregate as the whole of England, and then repeat this for each LEA, treating each of these in turn as the aggregate.

\section{Results}

We provide results under two main headings - an analysis of national patterns of ethnic segregation in schools and neighbourhoods, and a discussion of some selected local areas. In the former, we present results for all of our ethnic groups and also focus in particular on two aggregated groups - 'Black' and 'South Asian'. We concentrate here on describing the results, setting out the facts.

\section{(a) National Patterns}

We begin in Table 4 with the overall national segregation indices, both the $D$ and $I$ indices for all ethnic groups, for both schools and neighbourhoods. We see values for the $D$ indices of 0.448 (for children of Chinese ethnic origin) to 0.773 (Bangladeshi) in schools, and 0.522 to 0.754 for the same two groups in neighbourhoods. For the $I$ indices, values tend to be higher for the South Asian groups (0.209 for children with Indian ethnic origin, 0.288 for Bangladeshi) than for the Black groups $(0.101$ for children with Black Caribbean heritage, 0.115 for Black African). We do not draw any strong conclusions from these numbers as they are at too high a level of aggregation. They describe segregation across England as a whole. They are therefore dependent on the broad geographical spread of the different groups, which is far from even (see Burgess and Wilson (2003) for a map). We argue that taking this broad spread as given and looking at segregation at a more local level is more revealing.

Tables 5 and 6 do precisely this. We compute the $D$ index for each LEA for each group. These numbers address the following question: taking the ethnic composition of the LEA as given, how are the pupils from the different groups arranged across space in terms of their ethnicity? Are they integrated or segregated within the LEA? We are interested in the distribution of the $D$ indices across LEAs - the average value, but also the spread and the extremes. In Table 5a we display for each ethnic group the mean value of the $D$ index across 144 LEAs, alongside the 10th, 25th, 50th, 75th and 90th percentiles, and the maximum value. This is computed across children assigned to schools. Table $6 \mathrm{a}$ repeats the exercise for children (households) assigned to neighbourhoods. Finally, we repeat this for the $I$ index, presenting the same results in Table $5 \mathrm{~b}$ for schools and $6 \mathrm{~b}$ for neighbourhoods. 
Table 4: Ethnic segregation across schools and neighbourhoods, National level

\begin{tabular}{lcccc}
\hline \hline & $\begin{array}{c}\text { Dissimilarity } \\
\text { Index: schools }\end{array}$ & $\begin{array}{c}\text { Dissimilarity } \\
\text { Index: wards }\end{array}$ & $\begin{array}{c}\text { Isolation Index: } \\
\text { schools }\end{array}$ & $\begin{array}{c}\text { Isolation Index: } \\
\text { wards }\end{array}$ \\
\hline Black, Caribbean heritage & 0.709 & 0.718 & 0.101 & 0.078 \\
Black, African heritage & 0.746 & 0.741 & 0.115 & 0.104 \\
Black, other heritage & 0.652 & 0.730 & 0.057 & 0.022 \\
Indian ethnic origin & 0.688 & 0.657 & 0.209 & 0.176 \\
Pakistani ethnic origin & 0.756 & 0.748 & 0.256 & 0.226 \\
Bangladeshi ethnic origin & 0.773 & 0.754 & 0.288 & 0.228 \\
Chinese ethnic origin & 0.448 & 0.522 & 0.009 & 0.017 \\
Other minority ethnic origin & 0.613 & 0.397 & 0.175 & 0.039 \\
& & & & \\
South Asian & 0.698 & 0.679 & 0.324 & 0.281 \\
Black & 0.687 & 0.713 & 0.199 & 0.178 \\
\hline \hline
\end{tabular}

Source of Data: 2001 Annual Schools Census, 2001 Census 
Table 5a: Ethnic segregation across schools, LEA level: Dissimilarity index

\begin{tabular}{lccccccc}
\hline \hline & Mean & p10 & p25 & p50 & p75 & p90 & Max \\
\hline Black Caribbean heritage & 0.530 & 0.277 & 0.426 & 0.540 & 0.632 & 0.755 & 0.954 \\
Black African heritage & 0.497 & 0.293 & 0.395 & 0.489 & 0.612 & 0.654 & 0.858 \\
Black other heritage & 0.505 & 0.312 & 0.417 & 0.490 & 0.590 & 0.715 & 0.897 \\
Indian ethnic origin & 0.481 & 0.306 & 0.400 & 0.474 & 0.555 & 0.656 & 0.860 \\
Pakistani ethnic origin & 0.610 & 0.396 & 0.510 & 0.627 & 0.715 & 0.773 & 0.961 \\
Bangladeshi ethnic origin & 0.630 & 0.394 & 0.498 & 0.650 & 0.743 & 0.840 & 0.973 \\
Chinese ethnic origin & 0.396 & 0.284 & 0.346 & 0.399 & 0.444 & 0.503 & 0.658 \\
Other minority ethnic origin & 0.416 & 0.267 & 0.318 & 0.404 & 0.499 & 0.553 & 0.947 \\
& & & & & & & \\
South Asian & 0.491 & 0.320 & 0.400 & 0.501 & 0.589 & 0.643 & 0.716 \\
Black & 0.394 & 0.236 & 0.340 & 0.399 & 0.454 & 0.553 & 0.653 \\
\hline \hline
\end{tabular}

Weighted by relevant numbers

The $\mathrm{p} 50$ etc values refer to the 50th percentile of the relevant distribution

Source of Data: 2001 Annual Schools Census

Table 5b: Ethnic segregation across schools, LEA level: Isolation index

\begin{tabular}{lccccccc}
\hline \hline & Mean & p10 & p25 & p50 & p75 & p90 & Max \\
\hline Black, Caribbean heritage & 0.062 & 0.011 & 0.019 & 0.030 & 0.063 & 0.123 & 0.954 \\
Black, African heritage & 0.044 & 0.007 & 0.015 & 0.026 & 0.052 & 0.096 & 0.494 \\
Black, other heritage & 0.048 & 0.010 & 0.017 & 0.029 & 0.054 & 0.106 & 0.513 \\
Indian ethnic origin & 0.054 & 0.010 & 0.018 & 0.037 & 0.069 & 0.126 & 0.380 \\
Pakistani ethnic origin & 0.099 & 0.020 & 0.034 & 0.070 & 0.134 & 0.228 & 0.857 \\
Bangladeshi ethnic origin & 0.102 & 0.009 & 0.030 & 0.066 & 0.137 & 0.257 & 0.797 \\
Chinese ethnic origin & 0.026 & 0.006 & 0.010 & 0.018 & 0.030 & 0.054 & 0.232 \\
Other minority ethnic origin & 0.057 & 0.008 & 0.013 & 0.024 & 0.044 & 0.082 & 0.784 \\
& & & & & & & \\
South Asian & 0.091 & 0.012 & 0.023 & 0.060 & 0.136 & 0.234 & 0.421 \\
Black & 0.034 & 0.008 & 0.011 & 0.024 & 0.044 & 0.080 & 0.257 \\
\hline \hline
\end{tabular}

Weighted by relevant numbers

The p50 etc values refer to the 50th percentile of the relevant distribution

Source of Data: 2001 Annual Schools Census 
Table 6a: Ethnic segregation across neighbourhoods, LEA level:

Dissimilarity index

\begin{tabular}{lccccccc}
\hline \hline & Mean & $\mathbf{p 1 0}$ & $\mathbf{p 2 5}$ & $\mathbf{p 5 0}$ & $\mathbf{p 7 5}$ & $\mathbf{p 9 0}$ & Max \\
\hline Black, Caribbean heritage & 0.640 & 0.209 & 0.378 & 0.739 & 0.880 & 0.938 & 0.988 \\
Black, African heritage & 0.638 & 0.245 & 0.469 & 0.675 & 0.868 & 0.924 & 0.980 \\
Black, other heritage & 0.705 & 0.218 & 0.545 & 0.830 & 0.948 & 0.961 & 0.989 \\
Indian ethnic origin & 0.528 & 0.300 & 0.389 & 0.512 & 0.641 & 0.799 & 0.932 \\
Pakistani ethnic origin & 0.676 & 0.381 & 0.563 & 0.710 & 0.845 & 0.928 & 0.996 \\
Bangladeshi ethnic origin & 0.695 & 0.341 & 0.591 & 0.751 & 0.857 & 0.939 & 0.983 \\
Chinese ethnic origin & 0.512 & 0.273 & 0.375 & 0.529 & 0.646 & 0.729 & 0.936 \\
Other minority ethnic origin & 0.255 & 0.125 & 0.184 & 0.259 & 0.323 & 0.368 & 0.521 \\
& & & & & & & \\
South Asian & 0.524 & 0.296 & 0.419 & 0.549 & 0.617 & 0.727 & 0.863 \\
Black & 0.550 & 0.228 & 0.376 & 0.556 & 0.712 & 0.829 & 0.985 \\
\hline \hline
\end{tabular}

Weighted by relevant numbers

The p50 etc values refer to the 50th percentile of the relevant distribution

Source of Data: 2001 Census

Table 6b: Ethnic segregation across neighbourhoods, LEA level: Isolation index

\begin{tabular}{lccccccc}
\hline \hline & Mean & $\mathbf{p 1 0}$ & $\mathbf{p 2 5}$ & $\mathbf{p 5 0}$ & $\mathbf{p 7 5}$ & $\mathbf{p 9 0}$ & Max \\
\hline Black, Caribbean heritage & 0.065 & 0.007 & 0.011 & 0.023 & 0.059 & 0.172 & 0.979 \\
Black, African heritage & 0.049 & 0.008 & 0.011 & 0.022 & 0.048 & 0.111 & 0.618 \\
Black, other heritage & 0.078 & 0.008 & 0.011 & 0.033 & 0.076 & 0.207 & 0.985 \\
Indian ethnic origin & 0.048 & 0.009 & 0.015 & 0.029 & 0.063 & 0.117 & 0.222 \\
Pakistani ethnic origin & 0.093 & 0.011 & 0.022 & 0.060 & 0.132 & 0.233 & 0.583 \\
Bangladeshi ethnic origin & 0.077 & 0.010 & 0.016 & 0.040 & 0.096 & 0.170 & 0.781 \\
Chinese ethnic origin & 0.027 & 0.009 & 0.013 & 0.018 & 0.037 & 0.050 & 0.152 \\
Other minority ethnic origin & 0.012 & 0.005 & 0.008 & 0.011 & 0.014 & 0.021 & 0.049 \\
& & & & & & & \\
South Asian & 0.086 & 0.012 & 0.018 & 0.062 & 0.126 & 0.212 & 0.339 \\
Black & 0.037 & 0.009 & 0.012 & 0.020 & 0.048 & 0.073 & 0.985 \\
\hline \hline
\end{tabular}

Weighted by relevant numbers

The p50 etc values refer to the 50th percentile of the relevant distribution

Source of Data: 2001 Census 


\section{SCHOOLS}

We have discussed the schools-based results at greater length elsewhere (Burgess and Wilson, 2003). It is clear from Tables 5a and 5b that the mean level of segregation is high, averaging around 0.5 for children of Black Caribbean and Black African heritage, and above 0.6 for children of Pakistani or Bangladeshi ethnic origin. In other words, given the interpretation of the Dissimilarity index, over half the children would have to be notionally moved to obtain an even spread around the LEA. There is also a large range in the distribution: from 0.277 for at the 10th percentile to 0.755 at the 90 th percentile (for children of Black African origin). The group for which there is a smaller range is children of Chinese ethnic origin. At the upper end of the distribution, we see high values of segregation - $10 \%$ of LEAs have segregation levels for children of Pakistani origin above 0.773 . This means that for this minority of LEAs, segregation is very high, and around four fifths of the children would need to be notionally moved to create an even distribution across schools in the LEA. Much the same comments can be made of the $I$ index results in Table $5 \mathrm{~b}$, although the means are generally lower relative to the 'high' thresholds proposed by Massey and Denton (1993) than for the $D$ index -0.6 and 0.3 respectively.

Figure 1 graphs the $D$ index in each LEA against the $I$ index for the same LEA for selected ethnic groups and the two aggregated groups. This therefore shows both the full range of values, weighted by the number of pupils of that group, and also how the two indices compare. The size of the circle plotting the observation represents the number of pupils of that ethnicity in the LEA, ${ }^{14}$ so a larger circle means a more important data point.

14 The weights are only meaningful within a graph - the sizes of circle are the same between panels of the graph. 
Figure 1: Plot of D index against I index: schools, all LEAs (weighted by group numbers in LEA)
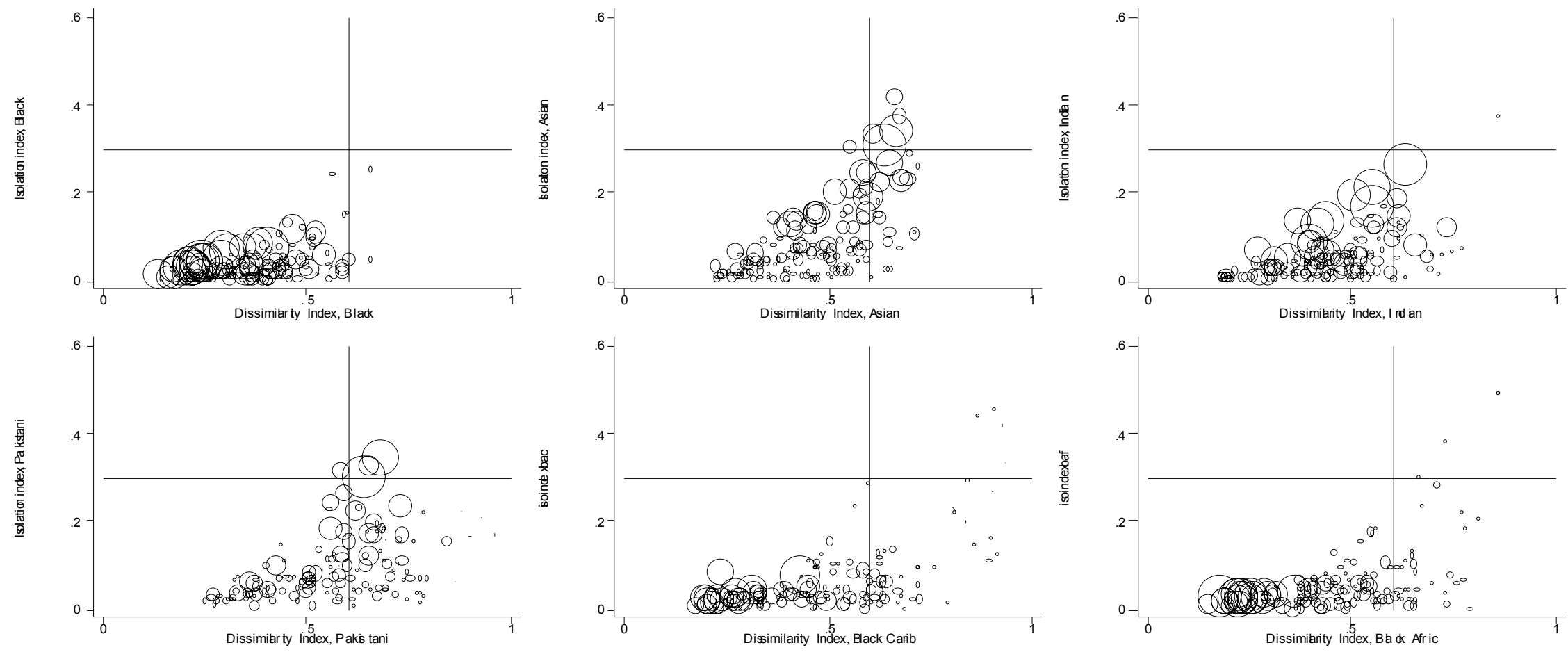
We argue that these tables and figures suggest high levels of segregation for the different groups, that there is considerable variation in segregation across England, and that segregation is generally higher for South Asian pupils than Black pupils. The data also suggest that segregation tends to be lower for Black pupils where they are relatively numerous, but that no such attenuation exists for pupils of South Asian origin (as illustrated in Figure 1 by the relative positions of the large circles). Finally, for Black pupils there are no LEAs where segregation is measured to be high along both dimensions, but that there are a few such places for pupils of South Asian origins, and furthermore these are LEAs where that group is relatively numerous.

\section{NEIGHBOURHOODS}

Tables $6 \mathrm{a}$ and $6 \mathrm{~b}$ present the same results for segregation across neighbourhoods (wards). There are both differences and similarities with the comparable schools tables. ${ }^{15}$ Looking first at the $D$ index results, the values are of roughly the same order of magnitude, the neighbourhood means being slightly higher than the school means for pupils of South Asian origin and considerably higher for Black pupils. There is also a greater range in the neighbourhood values across LEAs. In the neighbourhood results, there is less of a difference between Blacks and South Asians. Indeed, the $D$ index for students of Indian origin, are lower than for the other south Asian or Black groups. Turning to the $I$ index results, as with the schools-based data, the difference between Black students and South Asian students is much more pronounced.

We compare the neighbourhood-based $D$ and $I$ indices across LEAs in Figure 2. Again we see a number of distinct differences between the outcomes for Black pupils and pupils of South Asian origin. First, most of the LEAs with significant numbers of Black pupils have relatively low scores on both indices - the larger circles are clustered around the bottom left corner of the graph. However, the LEAs with many South Asian pupils typically have higher scores on both indices. This makes the high levels of segregation more of an issue, as they affect more individuals. This includes places like Bradford and Oldham.

\section{COMPARING SCHOOLS AND NEIGHBOURHOODS}

Since we see essentially the same children ${ }^{16}$ assigned across schools and neighbourhoods in any one LEA, we can compare the degree of segregation in

15 Note that we are not here directly comparing the values for individual LEAs for schools and neighbourhoods (see below), this compares the distribution in that the LEA at the $75^{\text {th }}$ percentile of the schools distribution may not be the same LEA as at the $75^{\text {th }}$ percentile of the wards distribution.

Subject to the data issues noted above. 
these two different (though obviously related) assignment mechanisms. We do this graphically in Figures 3 through 5. Figure 3 (respectively, 4) shows the $D$ index ( $I$ index) for each of the eight groups separately, weighted by the number of that group in each LEA. Figure 5 focuses on the two aggregated groups. In each graph, the segregation index based on neighbourhood is graphed on the horizontal axis, against the school-based index on the vertical axis; each observation is an LEA, scaled by the relative numbers of the ethnic group in that LEA. Many of the main points can be seen from Figure 3.

First, other than for pupils of Chinese and 'other' minority ethnicity (and possibly to some degree 'Black, other heritage'), the flow of points is generally along the $45^{\circ}$ line. ${ }^{17}$ That is to say, differences in school segregation across LEAs are generally in line with differences in residential segregation. This is as we would expect. Assignment to schools is related to residence, and so we would expect the two bases for segregation to produce similar results. Nonetheless, the two do not map one-for-one, and the two indices are generally not equal.

Second, for most of the ethnic groups, the weight of data generally suggests that the school-based indices are slightly greater than the neighbourhood-based indices, though the differences are marginal. That is to say, children are more segregated in school than where they live. This seems more clearly true of children with Black Caribbean heritage, children of Indian ethnicity, Pakistani ethnicity and Bangladeshi ethnicity, and less true of children with Black African or other Black heritage. This is particularly interesting given the discussion above suggesting that there is an inherent tendency for the geography to yield a higher set of indices for the neighbourhood-based measure. The patterns for pupils with Chinese and other minority ethnicity are really rather different, with increasing residential segregation not reflected in increasing school segregation.

17 Recall that these three categories were the least reliable from a data comparability point of view. 
Figure 2: Plot of D index against I index: wards, all LEAs (weighted by group numbers in LEA)
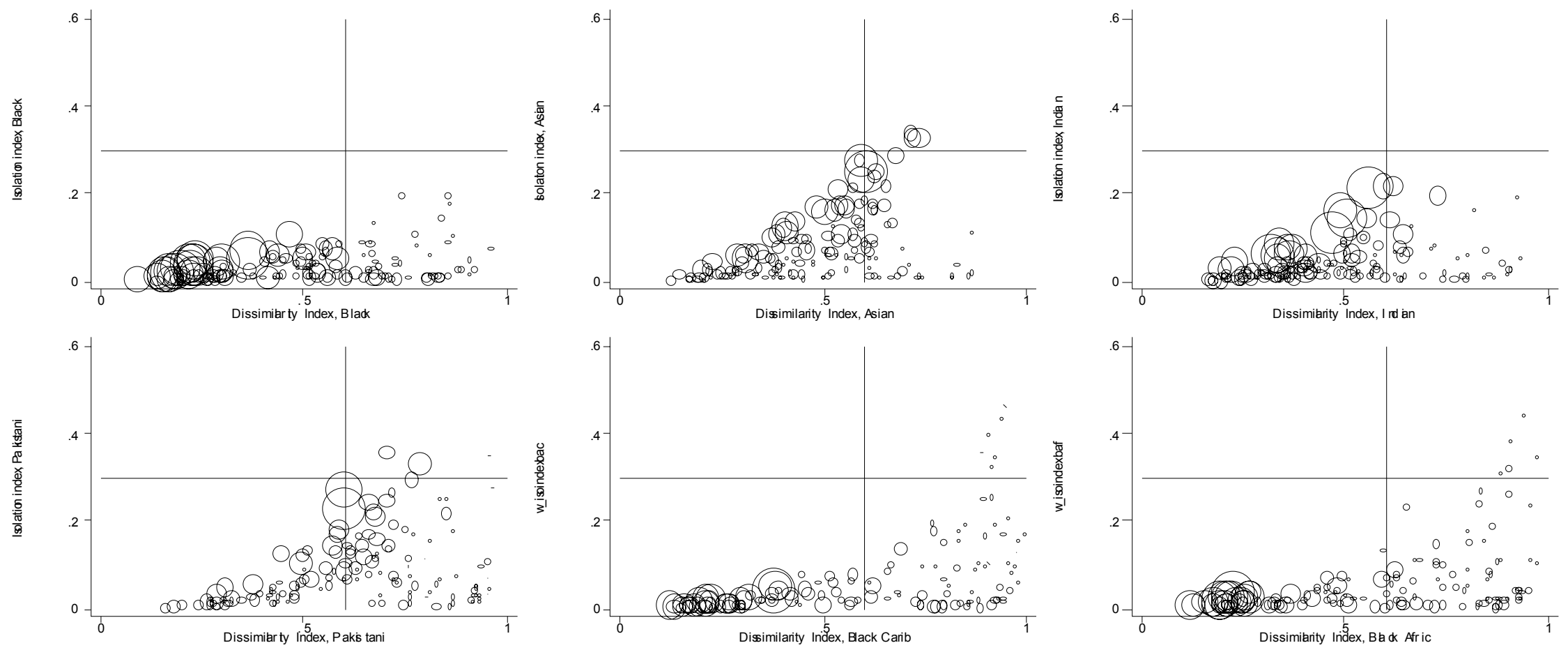

21 
Figure 3: Plot of ward-based against school-based D indices: all groups, weighted by numbers in group
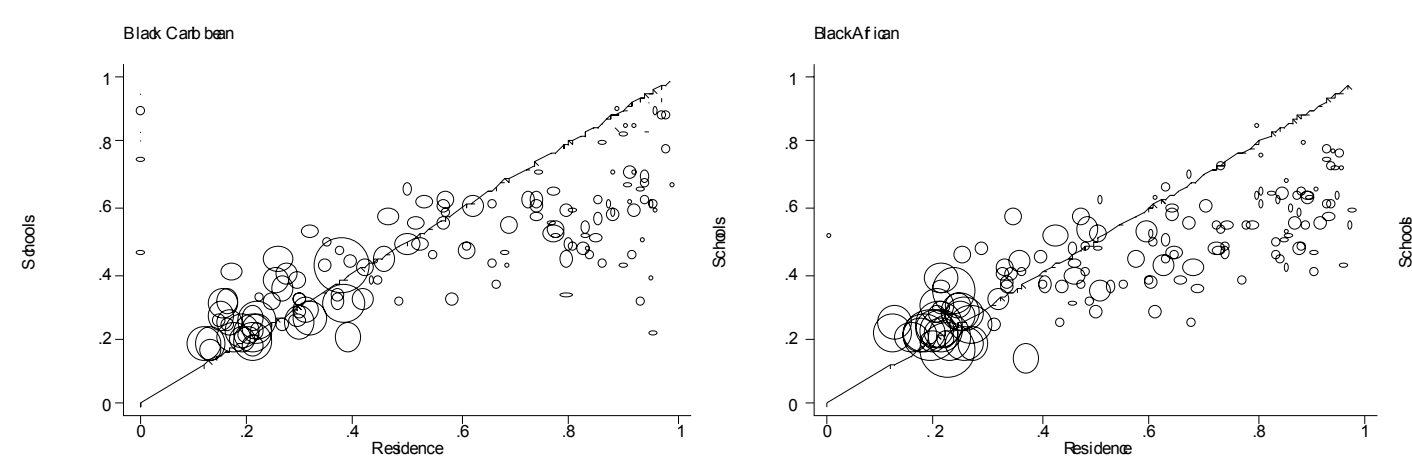

Blak a ter
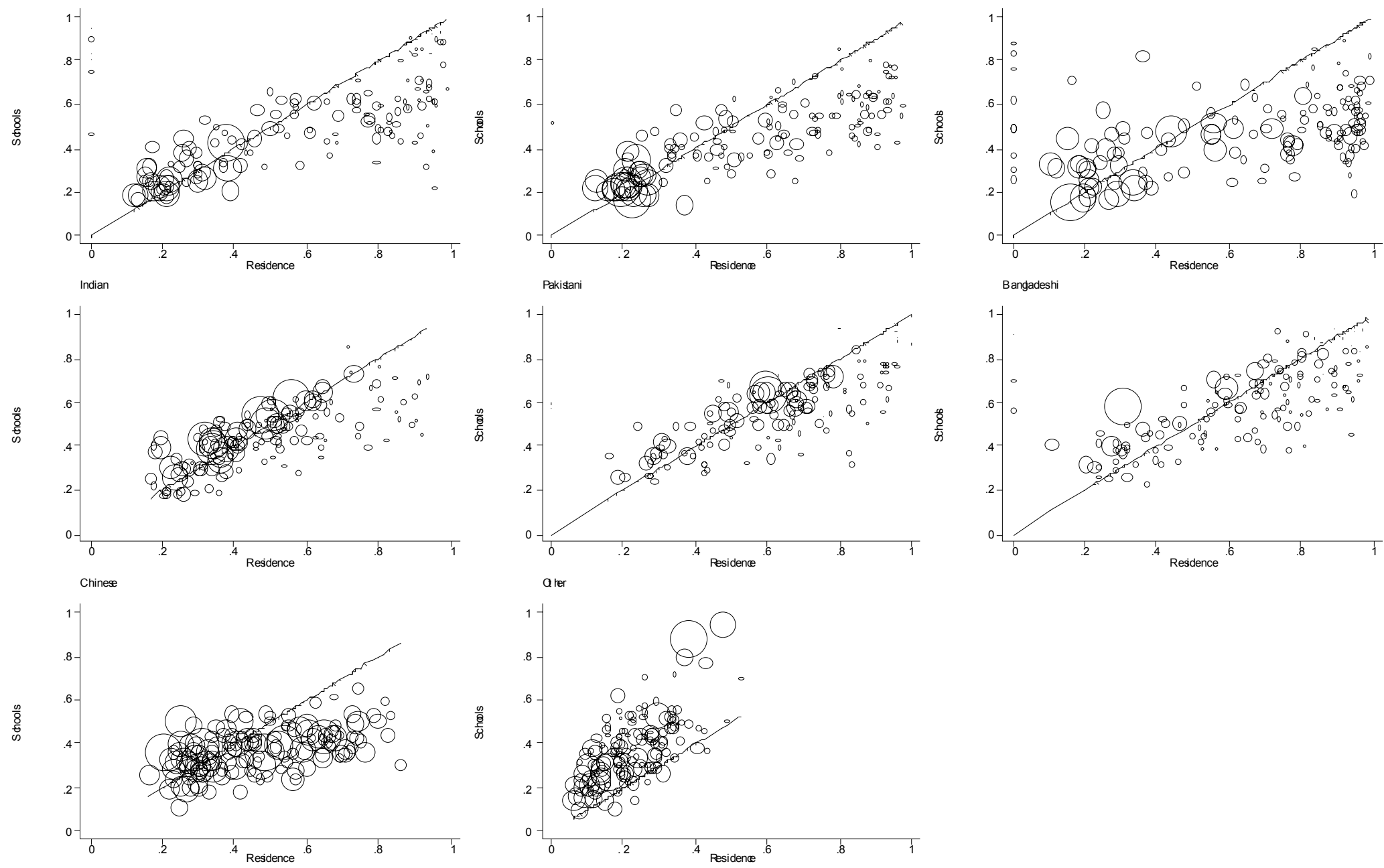
Figure 4: Plot of ward-based against school-based I indices: all groups, weighted by numbers in group
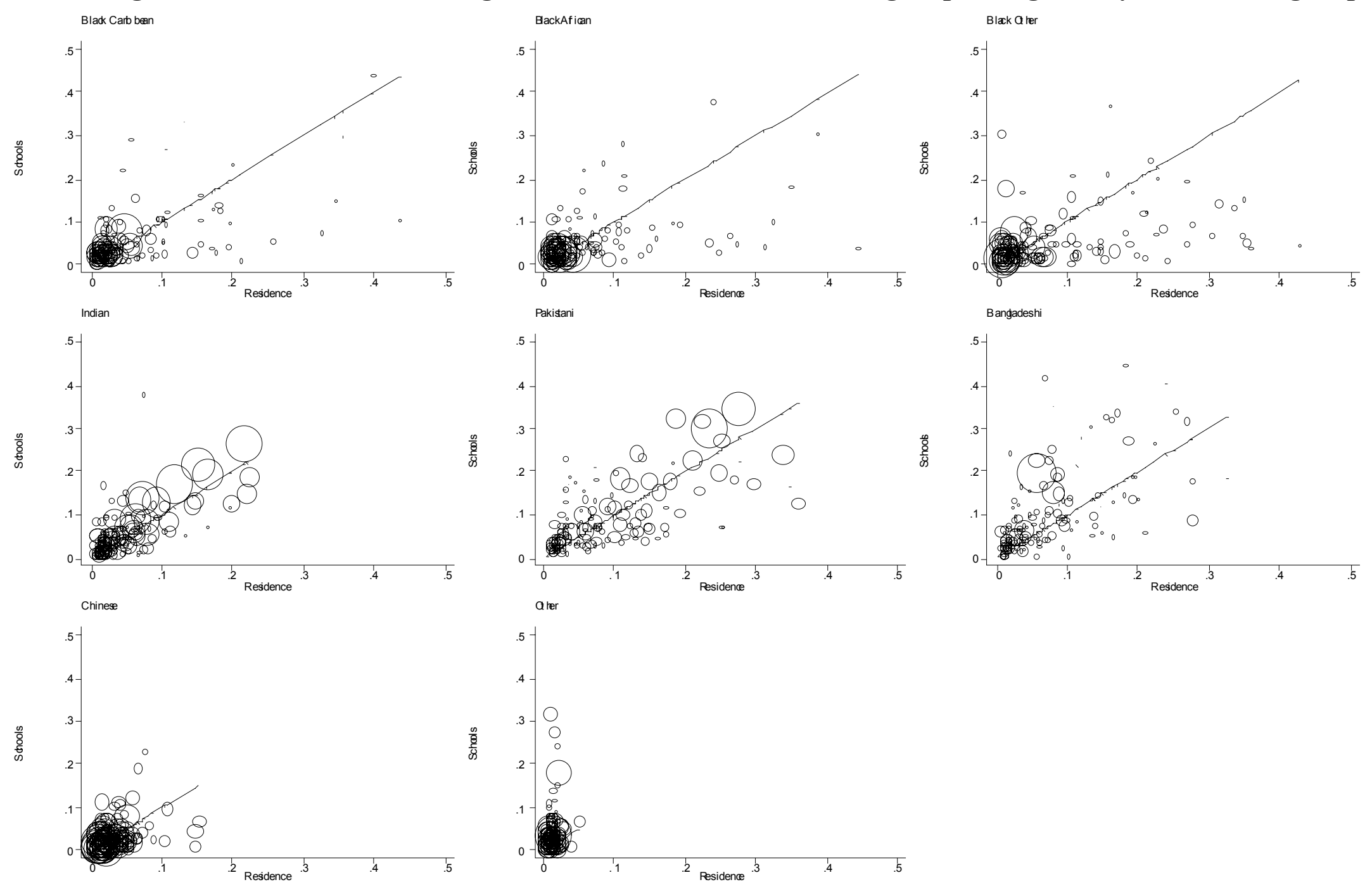
Third, we again see the differences between the segregation patterns of the different groups - LEAs with relatively large numbers of Black students tend to exhibit lower levels of segregation for them - this is particularly marked for students with Black African heritage. Conversely, children with Indian or Pakistani ethnicity tend to be more highly segregated when they are relatively more numerous. Here the degree of segregation is about constant with numbers (Indian) or increasing (Pakistani). The graph for students with Bangladeshi ethnicity is dominated by Tower Hamlets, by some margin the most important LEA of residence for this group, and exhibiting greater segregation (almost twice as high) in school than in residence.

Figures $5 \mathrm{a}-5 \mathrm{~d}$ make this comparison clearly. For Black pupils, Figure 5a shows that segregation is lowest where they are numerous. The set of highweight data points clustered in the bottom left corner of the figure are predominantly in London. The graph shows that overall, taking into account the number of Black students in each LEA, segregation is marginally greater in schools than in neighbourhoods. The same finding is confirmed in Figure $5 \mathrm{~b}$ using the $I$ index. The graph is plotted on the same scale as for the graph for South Asian students below, to reinforce the point that the numbers are very different for these two groups. But the relative point is maintained: the weighted data show that school segregation is higher than neighbourhood segregation.

For pupils with South Asian ethnicity, segregation is high where they are numerous, and also higher in schools than neighbourhoods. Figure 5c plots the $D$ index from the two datasets. Again, more of the weight of the data is above the line, more so than for Black students. The substantial outlier in the top left is Tower Hamlets. The larger datapoints in the upper right of the Figure include Blackburn, Bradford, Oldham and Birmingham. Figure $5 \mathrm{~d}$ uses the $I$ index and the difference with Figure $5 \mathrm{~b}$ is quite dramatic. It is clearer here that the LEAs with (relatively) large populations of this group see higher segregation in schools than wards.

It is worth recalling the point made above that the difference in size alone between wards and school catchment areas implies a higher level of segregation in neighbourhoods. Therefore these findings of a higher level on average in schools is probably an under-estimate of the true degree of difference between the two bases. 
Figure 5a: Plot of ward-based against school-based $D$ indices: aggregate 'Black' student group, weighted by numbers in group

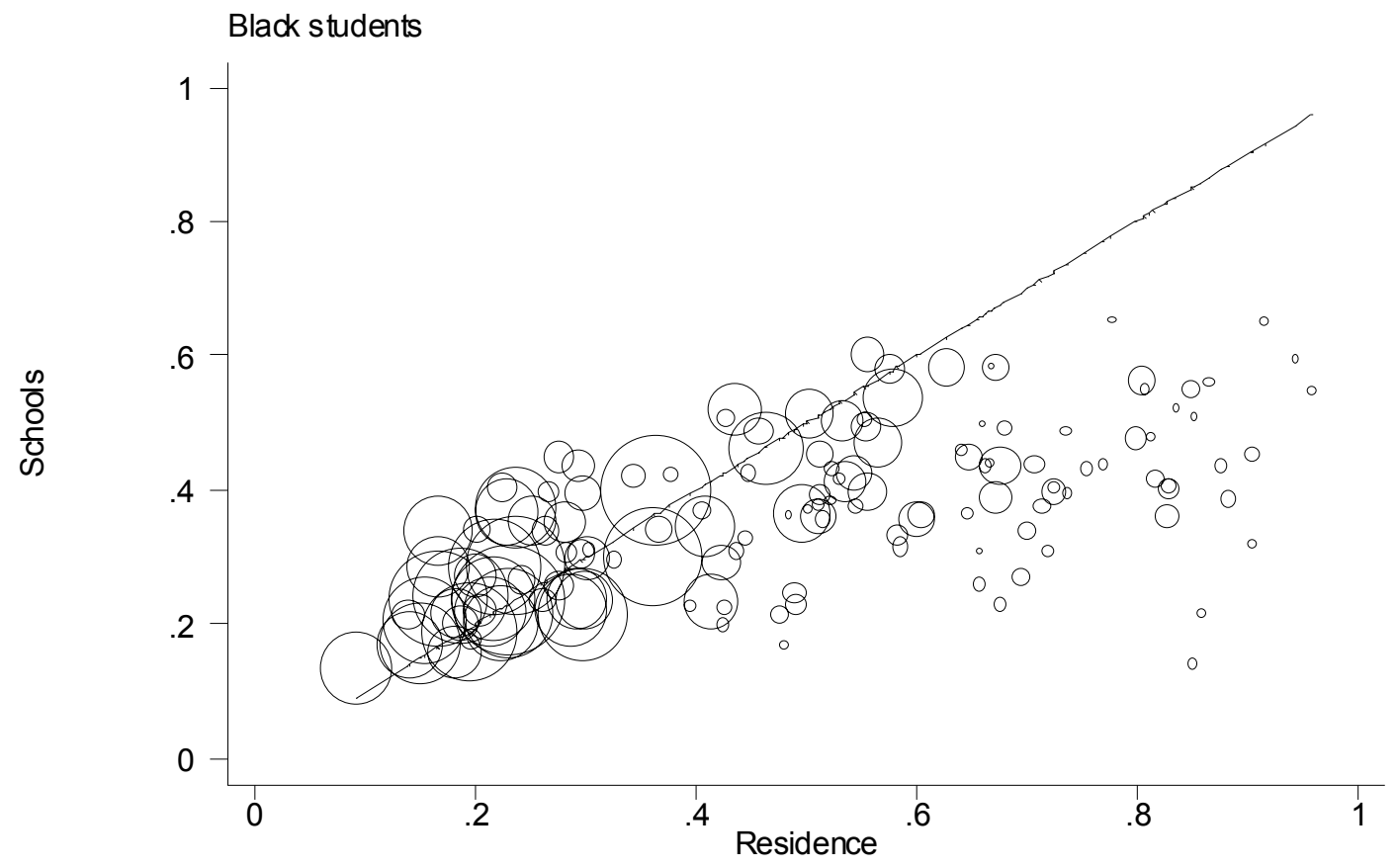

Figure 5b: Plot of ward-based against school-based I indices: aggregate 'Black' student group, weighted by numbers in group

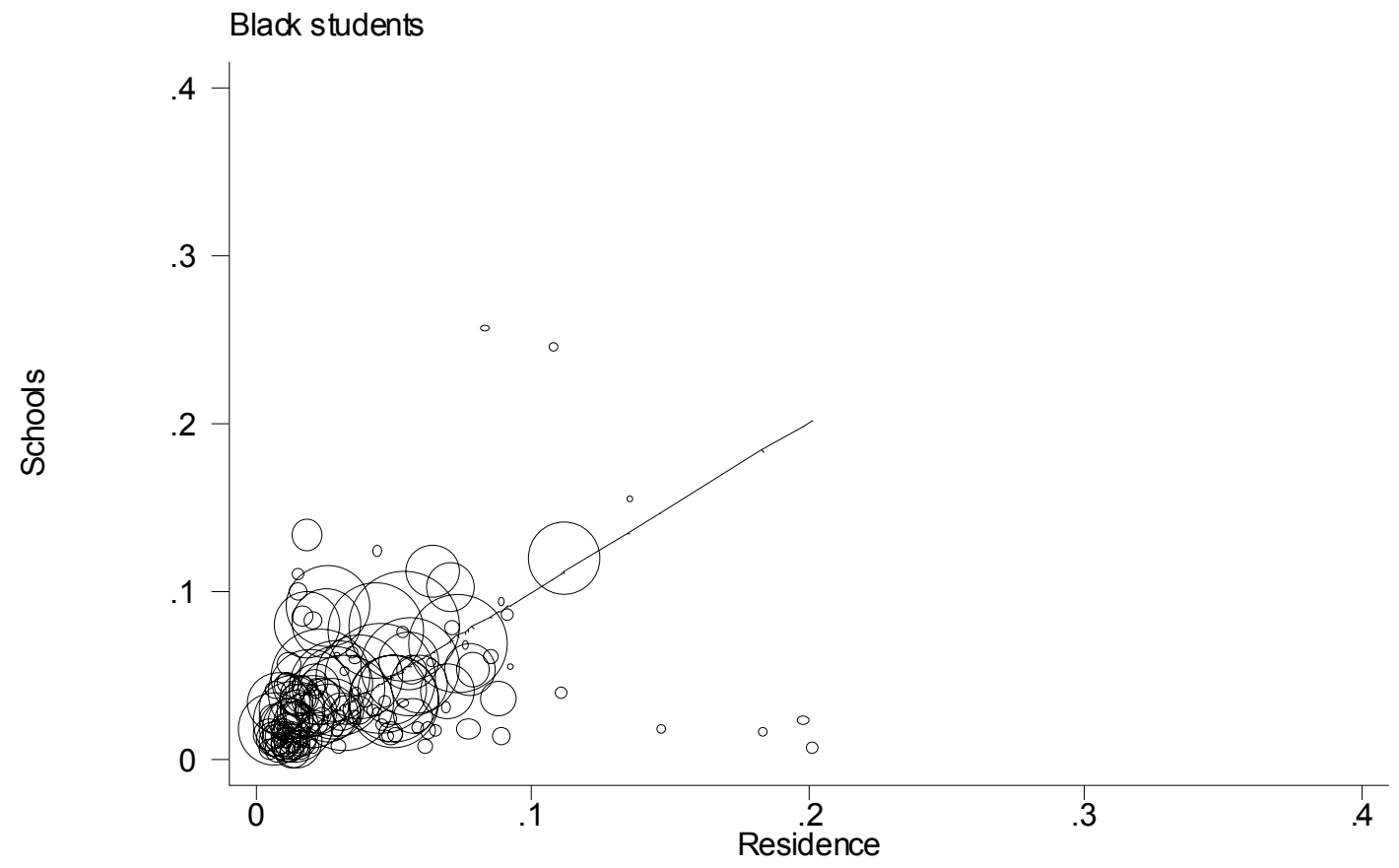


Figure 5c: Plot of ward-based against school-based $D$ indices: aggregate ' $S$ Asian' student group, weighted by numbers in group

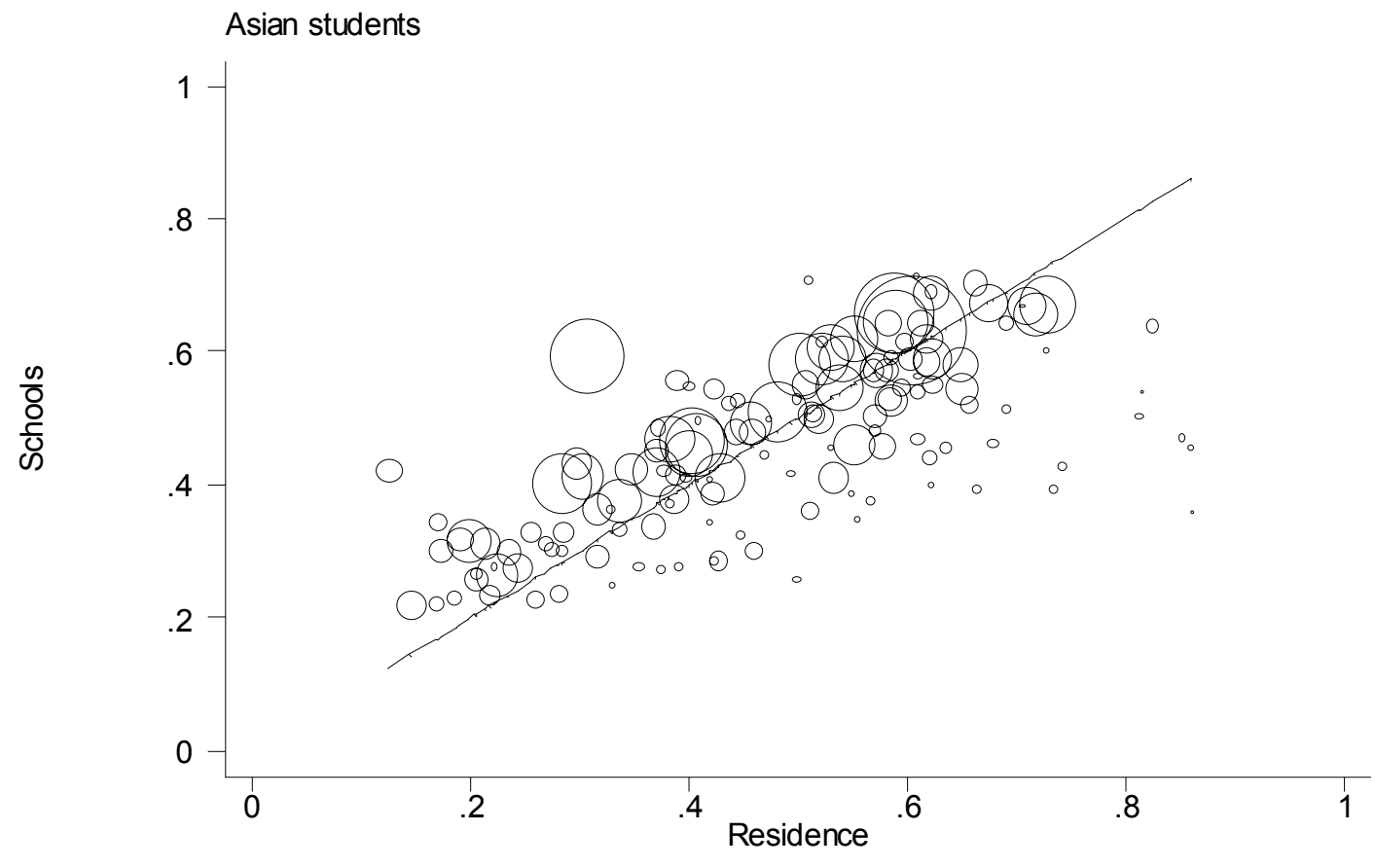

Figure 5d: Plot of ward-based against school-based I indices: aggregate ' $S$ Asian' student group, weighted by numbers in group

Asian students

.5

$.4-$

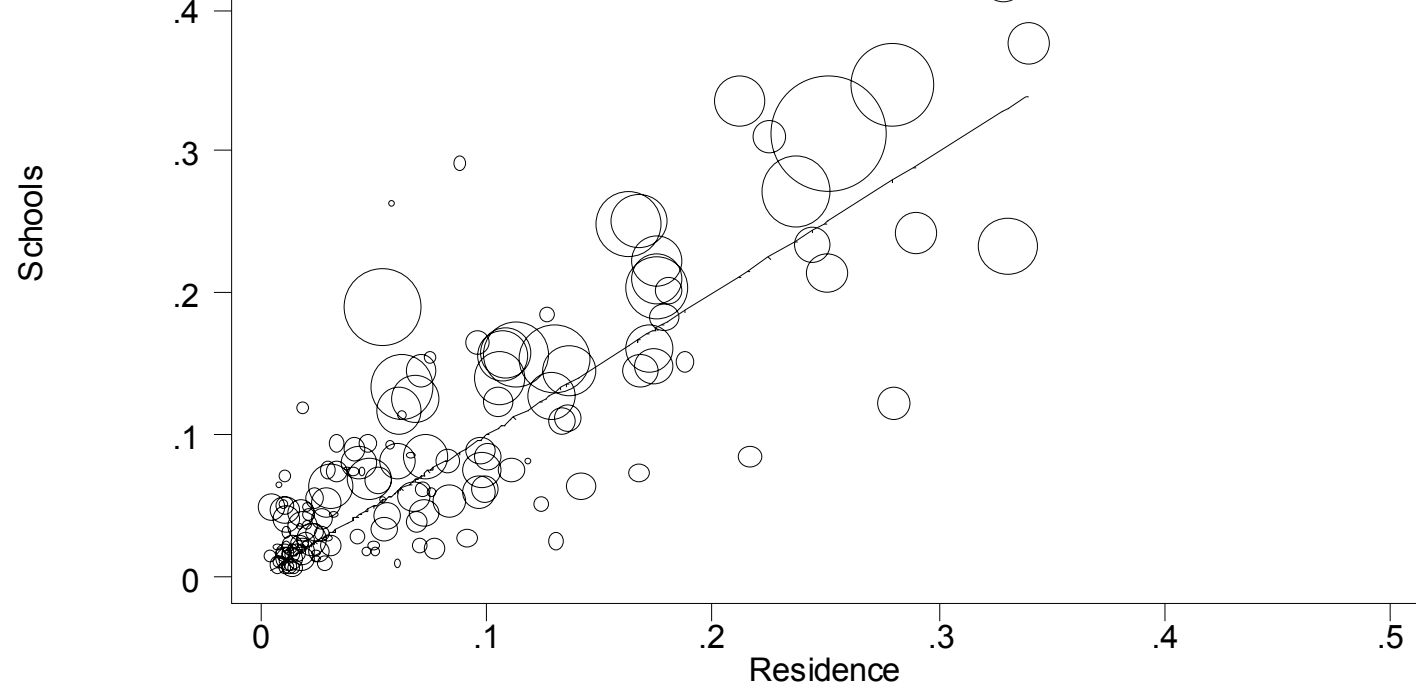


Next, we take London as the aggregate area within which we consider segregation, and consider all pairwise segregation indices. The results are in Table 7 (school-based) and Table 8 (neighbourhood-based). These show that levels of segregation differ between different minority ethnic groups, as well as between these and the majority, White population. Across both schools and neighbourhoods, for example, Black pupils are less segregated from each other than are students with South Asian ethnic origins. Bangladeshi students are the most highly segregated from all other groups. Comparison of Tables 7 and 8 shows that levels of segregation are higher across schools than across neighbourhoods in London: students in London are generally more segregated at school than in their neighbourhood. 
Table 7: Pairwise Dissimilarity indices for London: across schools

\begin{tabular}{|c|c|c|c|c|c|c|c|c|c|c|c|}
\hline & $\begin{array}{c}\text { Black } \\
\text { Caribbean }\end{array}$ & $\begin{array}{c}\text { Black } \\
\text { African }\end{array}$ & $\begin{array}{c}\text { Black } \\
\text { other }\end{array}$ & Indian & Pakistani & $\begin{array}{c}\text { Bangla- } \\
\text { deshi }\end{array}$ & Chinese & $\begin{array}{c}\text { Other } \\
\text { minority }\end{array}$ & S Asian & Black & $\begin{array}{c}\text { \% Pupils } \\
\text { in London }\end{array}$ \\
\hline Black Caribbean & & & & & & & & & & & 6.7 \\
\hline Black African & 0.261 & & & & & & & & & & 7.5 \\
\hline Black other & 0.383 & 0.421 & & & & & & & & & 3.2 \\
\hline Indian & 0.623 & 0.604 & 0.666 & & & & & & & & 8.6 \\
\hline Pakistani & 0.599 & 0.584 & 0.621 & 0.382 & & & & & & & 3.4 \\
\hline Bangladeshi & 0.712 & 0.662 & 0.729 & 0.749 & 0.691 & & & & & & 4.1 \\
\hline Chinese & 0.490 & 0.468 & 0.504 & 0.565 & 0.651 & 0.683 & & & & & 1.0 \\
\hline Other minority & 0.423 & 0.376 & 0.464 & 0.498 & 0.541 & 0.665 & 0.430 & & & & 7.4 \\
\hline S Asian & 0.583 & 0.542 & 0.608 & - & - & - & 0.557 & 0.483 & & & 16.2 \\
\hline Black & - & - & - & 0.608 & 0.579 & 0.677 & 0.451 & 0.363 & 0.546 & & 17.6 \\
\hline White & 0.528 & 0.524 & 0.511 & 0.616 & 0.680 & 0.758 & 0.400 & 0.459 & 0.617 & 0.492 & 57.8 \\
\hline
\end{tabular}

London Schools only (387); taking London as the aggregate spatial unit

Weighted by relevant numbers

Source of Data: 2001 Annual Schools Census 
Table 8: Pairwise Dissimilarity indices for London: across neighbourhoods

\begin{tabular}{|c|c|c|c|c|c|c|c|c|c|c|c|}
\hline & $\begin{array}{c}\text { Black } \\
\text { Caribbean }\end{array}$ & $\begin{array}{c}\text { Black } \\
\text { African }\end{array}$ & $\begin{array}{l}\text { Black } \\
\text { other }\end{array}$ & Indian & Pakistani & $\begin{array}{c}\text { Bangla- } \\
\text { deshi }\end{array}$ & Chinese & $\begin{array}{c}\text { Other } \\
\text { minority }\end{array}$ & S Asian & Black & $\begin{array}{l}\text { \% aged } \\
10-17 \text { in } \\
\text { London }\end{array}$ \\
\hline Black Caribbean & & & & & & & & & & & 5.8 \\
\hline Black African & 0.248 & & & & & & & & & & 7.5 \\
\hline Black other & 0.172 & 0.246 & & & & & & & & & 1.6 \\
\hline Indian & 0.580 & 0.570 & 0.608 & & & & & & & & 7.8 \\
\hline Pakistani & 0.517 & 0.534 & 0.540 & 0.363 & & & & & & & 3.0 \\
\hline Bangladeshi & 0.665 & 0.609 & 0.669 & 0.718 & 0.669 & & & & & & 4.1 \\
\hline Chinese & 0.466 & 0.384 & 0.445 & 0.551 & 0.593 & 0.660 & & & & & 1.2 \\
\hline Other minority & 0.327 & 0.298 & 0.332 & 0.437 & 0.442 & 0.635 & 0.326 & & & & 9.9 \\
\hline S Asian & 0.525 & 0.495 & 0.545 & & & - & 0.507 & 0.393 & & & 14.9 \\
\hline Black & & & & 0.568 & 0.517 & 0.629 & 0.407 & 0.289 & 0.496 & & 15.0 \\
\hline White & 0.528 & 0.469 & 0.492 & 0.560 & 0.583 & 0.703 & 0.381 & 0.302 & 0.544 & 0.468 & 59.1 \\
\hline
\end{tabular}

624 wards; taking London as the aggregate spatial unit

Weighted by relevant numbers

Source of Data: 2001 Census 


\section{REGRESSION ANALYSIS}

Finally in this section we investigate the differences across the country in the relationship between school and neighbourhood segregation. We take the ratio of school to ward segregation indices as our measure and relate this to a variety of LEA characteristics. The ones we focus on are: the numeric importance of the specific group in the LEA, population density in the LEA, poverty as measured by the LEA average of the ward-level index of multiple deprivation, and a set of others described below. Note that this is overall poverty for all ethnic groups: it is not specific to each single ethnic group. These regressions are in Table 9, separately for the $D$ and for the $I$ index ratios, and for each ethnic group (we omit Black other heritage; Chinese, and other minority ethnicity because of the concerns over the comparability of the groups between the two datasets). The regressions are weighted by the LEA fractions of the relevant group.

The main result is that population density is an important influence on the ratio. It is significantly positive for all groups for both indices. Thus in dense (urban) areas, we find that the school segregation index is higher relative to residential segregation indices. The results for the poverty variable are much less clear. There is a significant positive effect for students with Black Caribbean heritage, and for students of Bangladeshi ethnic origin. But there is a negative effect for students with Indian or Pakistani ethnic origin. Data on the income levels by ethnic group and LEA would of course be valuable.

We explored a number of other LEA characteristics: population size, percent of selective schools in the LEA, percentage of rural wards, a London dummy, a metropolitan area dummy, and a measure of average school performance in the LEA. None of these yielded any systematic results across indices and groups (results available from authors).

The importance of density is interesting. High density suggests that distances between schools and neighbourhoods are relatively short. It also suggests a thicker 'market' of school age children within a small area. These might lead to two pressures towards greater school segregation. First, parents and children have more schools to choose from within feasible travel times. Suppose parents have different preferences in terms of the ethnic mix they want for their child's school. Given more choice in an urban environment, they are more likely to be able to realise that preference. Second, schools have more scope to segment the market in a large market.

Density has a non-trivial effect - see Table 10 . We compute the percentage by which school segregation exceeds residential segregation at different levels of population density, holding the poverty rate constant. The table presents the 
results for different ethnic groups. For example, going from a population density of 0.1 to 0.38 , about one standard deviation, raises the percentage difference considerably across all groups. Of course, it needs to be remembered that this is only part of the process - this is simply about the difference between school and residential density - and neighbourhood segregation is not trivial. Thus while London shows the highest density, and so the highest difference, as we have seen above London has lower overall levels of both residential and school segregation.

\section{(b) Specific LEAs}

In this section we use the rich data at our disposal to consider a few areas more thoroughly, in order to add detail to the national picture presented above. We focus on seven specific LEAs to illustrate different patterns of ethnic mix. All were selected as having relatively numerous pupils from minority groups, and to illustrate different patterns of mix. For each area, we present two graphs - the upper one showing the ethnic composition of each school in the LEA, and the lower one the ethnic composition of each ward. So in the upper panel, each observation is a school, and in the lower panel, each observation is a ward. ${ }^{18}$ The composition is between White pupils and the two aggregate groups of Black pupils and pupils of South Asian ethnicity; the observations are ordered so as to increase in the percentage of the last of these.

What should we expect to see? Low segregation will appear as a set of more-orless flat lines, with each ethnic group spread evenly across all units. High segregation appears as some schools (wards) with $100 \%$ of one group and $0 \%$ of the other groups, flipping over to other schools (wards) with $0 \%$ of the first group and $100 \%$ of the others. Both these patterns are approximated here along with intermediate patterns. For example, take Islington, Figure 6a. The indices calculated above for Islington suggest that this is a low segregation area, and this figure bears that out clearly - the different groups are indeed fairly evenly spread out. Contrast this with the pictures for Oldham (Figure 6d), or Bradford (6e), or Blackburn (6g). Here, segregation in both schools and wards is very clear. Looking at Bradford in more detail, the graphs do seem to reflect higher segregation in schools than wards - there are more wards that might be described as mixed than there are schools. Slough (6f), Manchester (6c) and Birmingham (6b) are intermediate case with some highly segregated wards and schools, but also a good number of mixed ones.

In future work, we will map the schools on to the wards. 
Table 9: Explaining the School-Ward Segregation Ratio

Dissimilarity Index - Dependent variable is School D index/Ward D Index; unit of observation is the LEA

\begin{tabular}{lccccccc}
\hline \hline & $\begin{array}{c}\text { Black } \\
\text { Caribbean }\end{array}$ & $\begin{array}{c}\text { Black } \\
\text { African }\end{array}$ & Indian & Pakistani & Bangladeshi & South Asian & Black \\
\hline Density & 0.439 & 0.978 & 0.462 & 0.523 & 0.723 & 0.756 & 0.789 \\
& $(2.90)^{* *}$ & $(7.47)^{* *}$ & $(3.50)^{* *}$ & $(7.32)^{* *}$ & $(5.95)^{* *}$ & $(8.02)^{* *}$ & $(5.77)^{* *}$ \\
Poverty & 0.009 & 0.004 & -0.007 & -0.001 & 0.013 & -0.003 & 0.001 \\
& $(3.18)^{* *}$ & $(1.65)$ & $(2.92)^{* *}$ & $(0.89)$ & $(3.87)^{* *}$ & $(1.71)$ & $(0.27)$ \\
\# obs & 136 & 143 & 144 & 142 & 140 & 144 & 144 \\
R2 & 0.2 & 0.33 & 0.12 & 0.32 & 0.5 & 0.37 & 0.27 \\
\hline \hline
\end{tabular}

Isolation Index - Dependent variable is School I index/Ward I Index; unit of observation is the LEA

\begin{tabular}{lccccccc}
\hline \hline & $\begin{array}{c}\text { Black } \\
\text { Caribbean }\end{array}$ & $\begin{array}{c}\text { Black } \\
\text { African }\end{array}$ & Indian & Pakistani & Bangladeshi & South Asian & Black \\
\hline Density & 1.442 & 2.019 & 2.423 & 2.125 & 2.645 & 2.111 & 2.259 \\
& $(2.31)^{*}$ & $(3.61)^{* *}$ & $(3.37)^{* *}$ & $(6.30)^{* *}$ & $(3.33)^{* *}$ & $(5.13)^{* *}$ & $(4.52)^{* *}$ \\
Poverty & 0.013 & -0.003 & -0.044 & -0.021 & 0.071 & -0.016 & -0.009 \\
& $(1.13)$ & $(0.29)$ & $(3.59)^{* *}$ & $(3.37)^{* *}$ & $(3.33)^{* *}$ & $(1.95)$ & $(1.07)$ \\
\# obs & 136 & 143 & 144 & 142 & 140 & 144 & 144 \\
R2 & 0.07 & 0.16 & 0.12 & 0.24 & 0.18 & 0.16 & 0.14 \\
\hline \hline
\end{tabular}

Also included in the regressions - constant and group own \%.

Weighted by group own \%.

Absolute value of t-statistics in parentheses; * significant at 5\% level; ** significant at $1 \%$ level. 
Table 10: Percentage difference of school D-index over ward D-index for various population density values

\begin{tabular}{lcccccccc}
\hline \hline Density & Example LEA & $\begin{array}{c}\text { Black } \\
\text { Caribbean }\end{array}$ & $\begin{array}{c}\text { Black } \\
\text { African }\end{array}$ & Indian & Pakistani & $\begin{array}{c}\text { Bangladesh } \\
\text { i }\end{array}$ & South Asian & Black \\
\hline 1 & Lambeth & 51.5 & 89.2 & 41.7 & 35.4 & 74.8 & 59.7 & 63.4 \\
0.38 & Birmingham & 24.3 & 28.6 & 13.1 & 3.0 & 30.0 & 12.9 & 14.5 \\
0.1 & Blackburn & 12.0 & 1.2 & 0.2 & -11.6 & 9.8 & -8.3 & -7.6 \\
0.015 & Norfolk & 8.3 & -7.1 & -3.8 & -16.1 & 3.6 & -14.7 & -14.3 \\
\hline \hline
\end{tabular}

The number is calculated using the regression coefficients from Table 9 as follows:

$\{\mathrm{D}($ school $)-\mathrm{D}($ ward $)\} * 100 / \mathrm{D}($ ward $)=\{($ constant + poverty coefficient $*$ poverty + density coefficient*density $)-1\} * 100$

where poverty is set to the weighted sample mean, weighted by the ethnic group-specific population percentage.

Density is measured as population $(10,000)$ per $\mathrm{km} 2$.

Distribution of density is:

Mean $\quad 0.248$

Std. Dev. 0.273

$10 \% \quad 0.014$

$25 \% \quad 0.038$

$50 \% \quad 0.161$

$75 \% \quad 0.370$

$90 \% \quad 0.561$ 
Figure 6a: Islington LEA
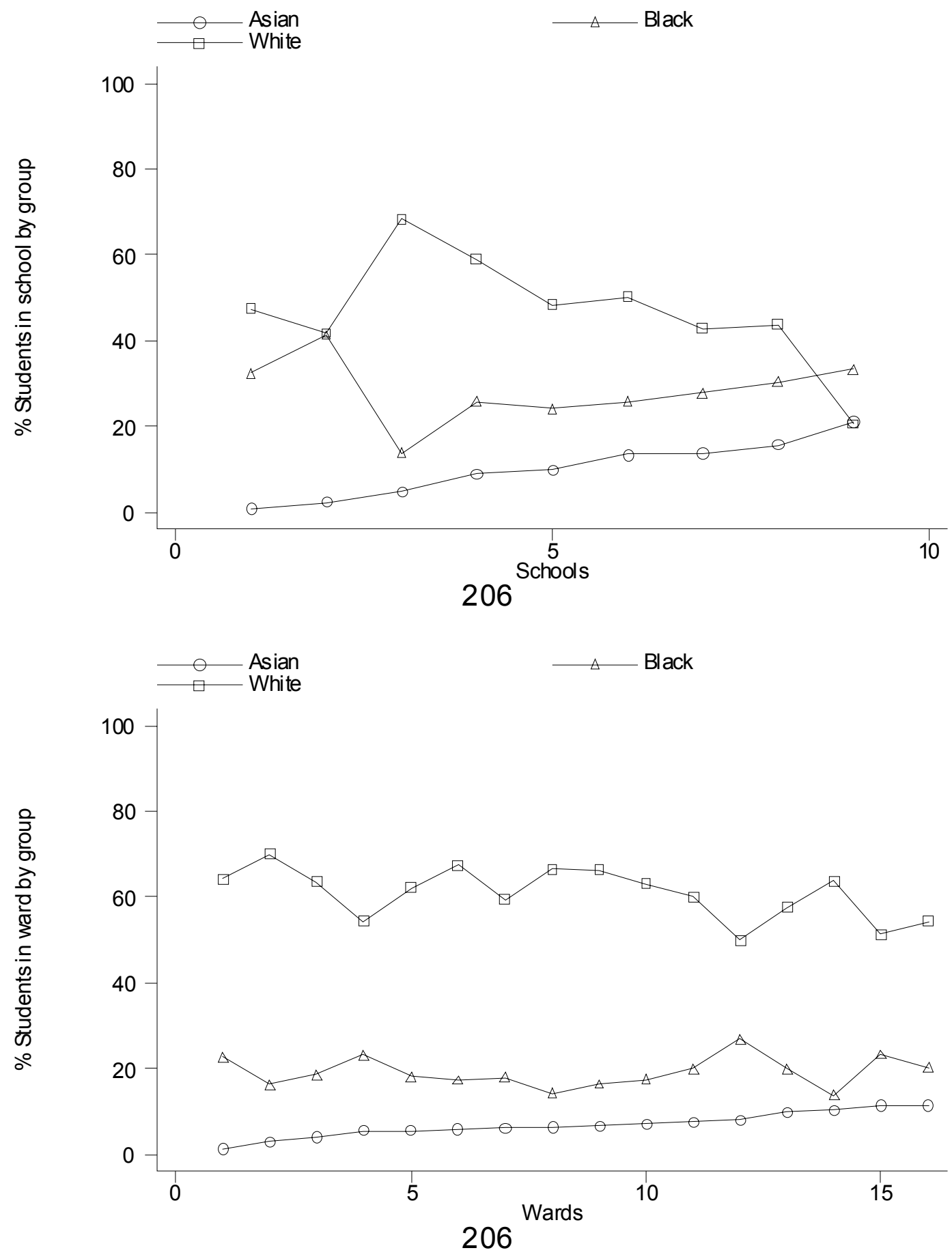


\section{Figure 6b: Birmingham LEA}
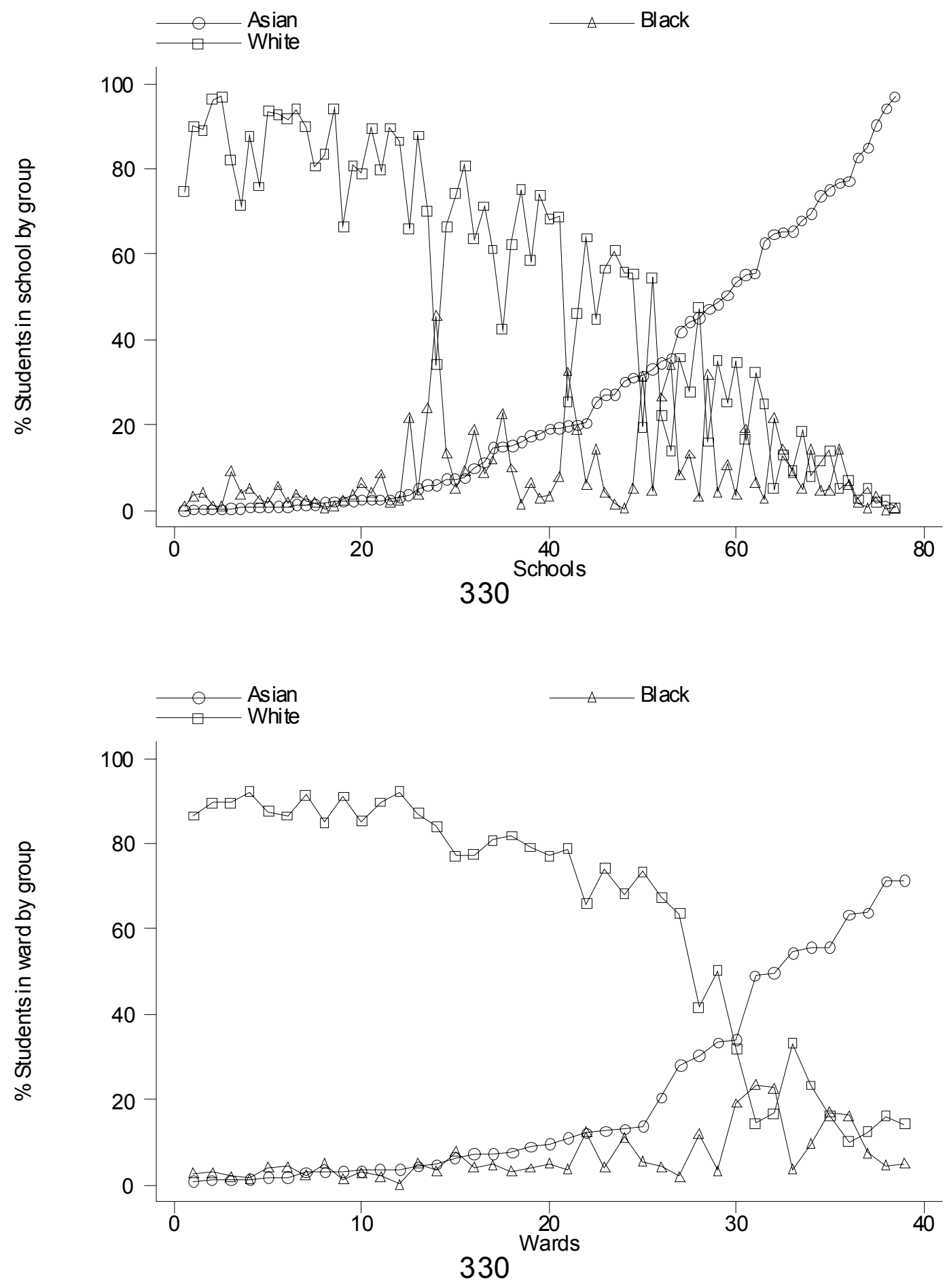
Figure 6c: Manchester LEA
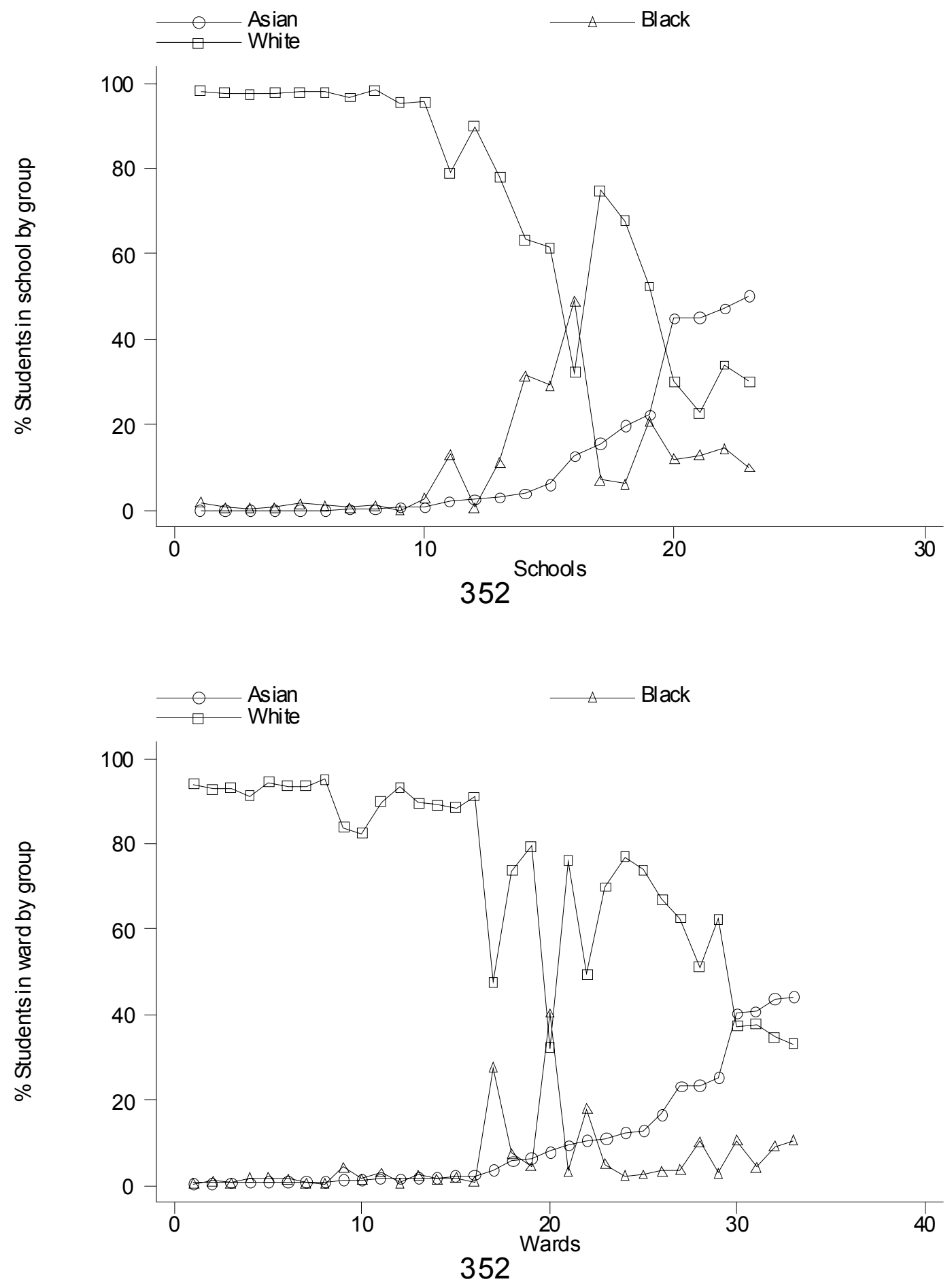
Figure 6d: Oldham LEA
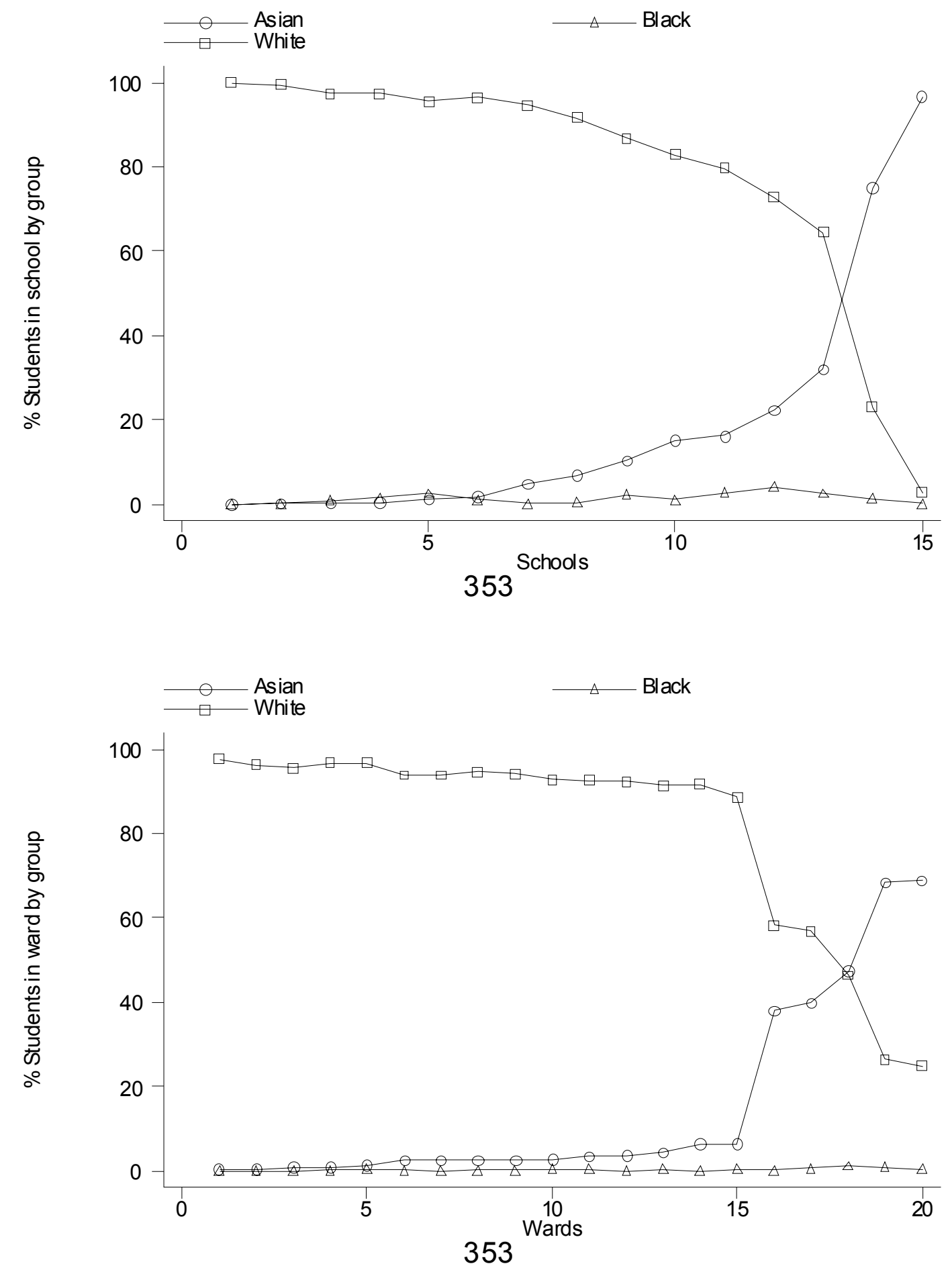
Figure 6e: Bradford LEA
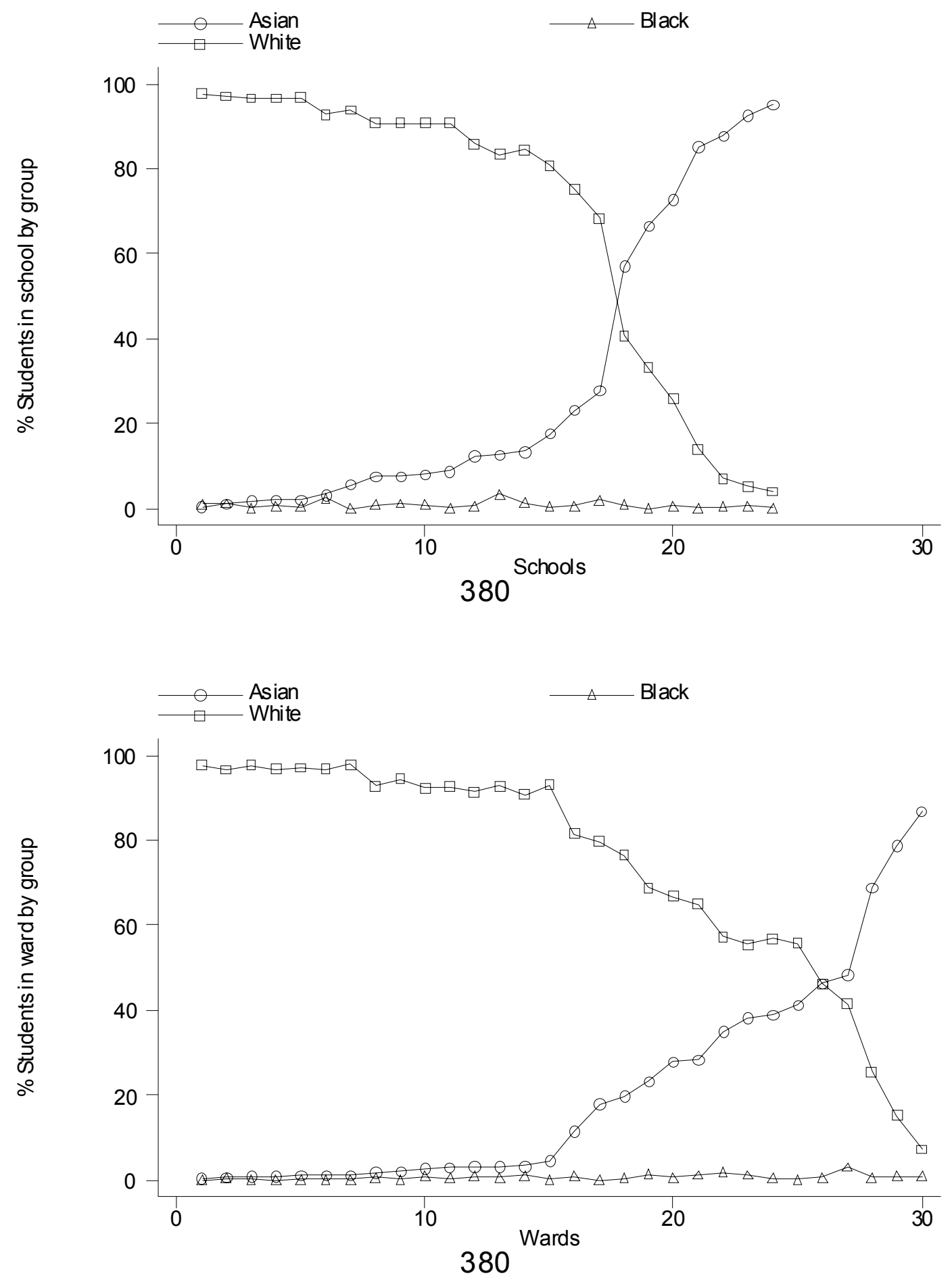
Figure 6f: Slough LEA
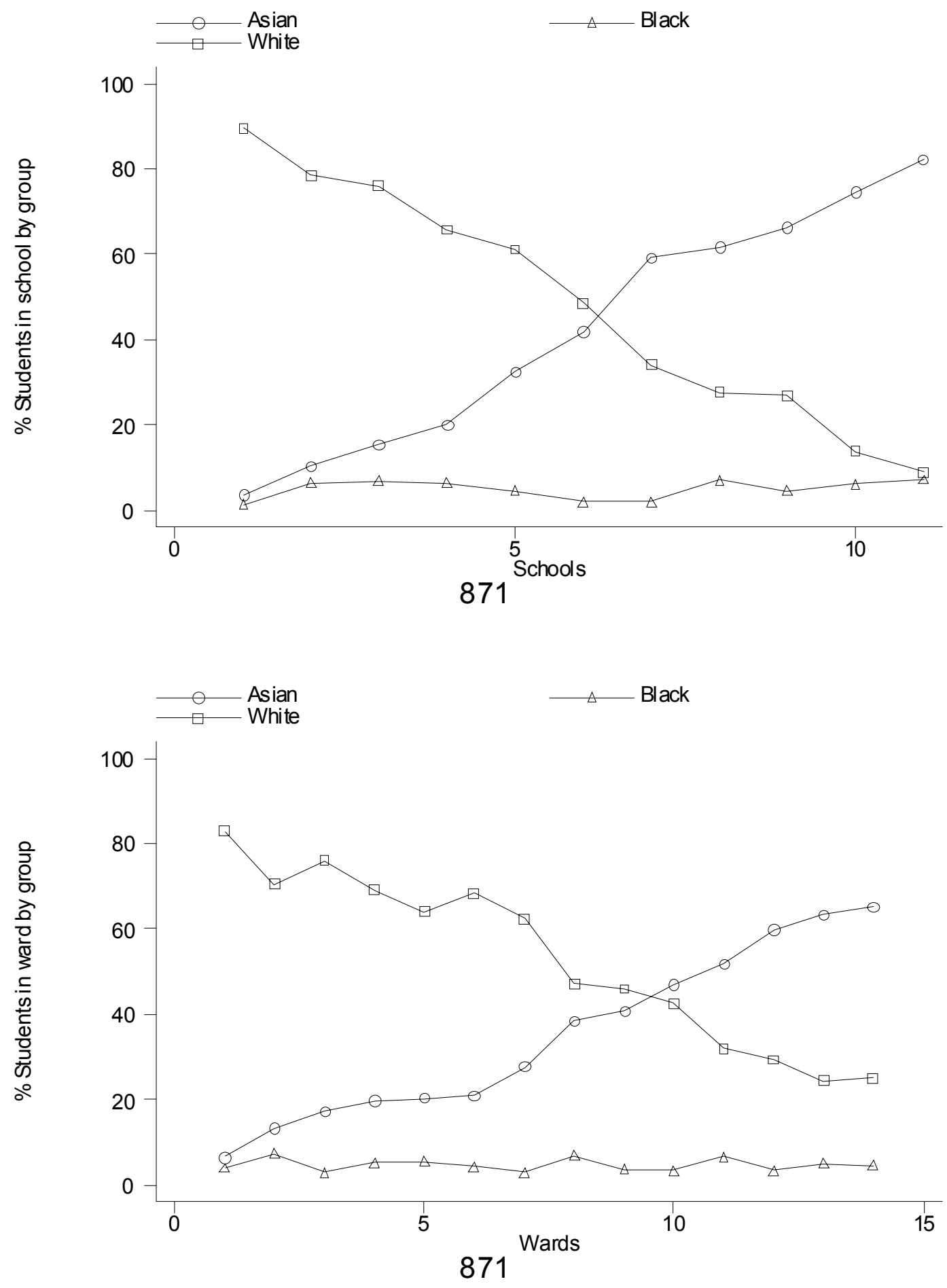


\section{Figure 6g: Blackburn LEA}
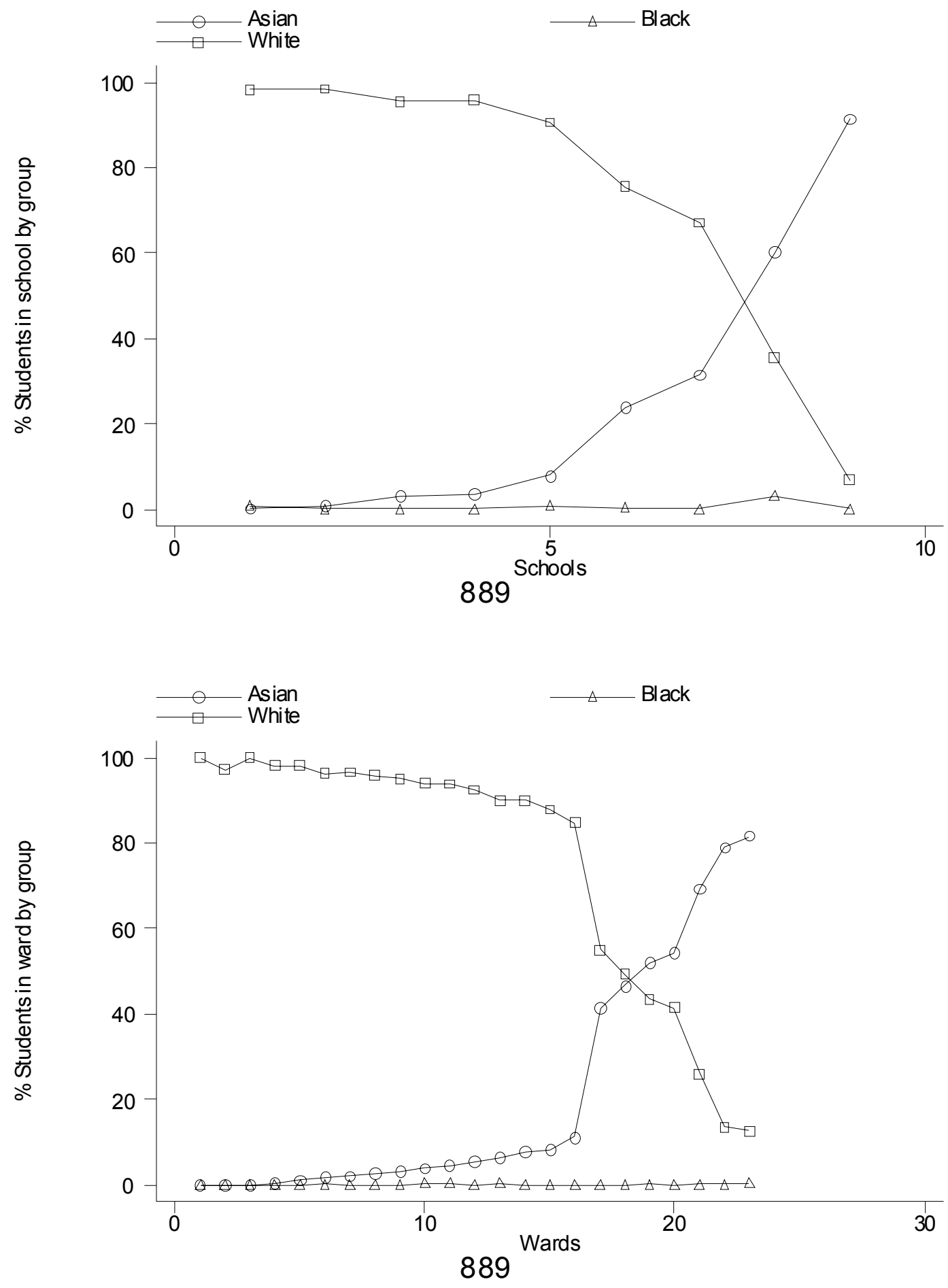


\section{Conclusion}

This paper provides some facts for the debate on ethnic segregation of England's secondary school-age children. Combining school-level data from the Annual Census of Schools for 2001 with ward-level data from the 2001 Census of Population, we have measured two aspects of segregation for nine different ethnic groups on these two different bases.

Looking at both schools and neighbourhoods, we find high levels of segregation for the different groups, along with considerable variation in segregation across England. We find consistently higher segregation for South Asian pupils than for Black pupils. The data also suggest that segregation tends to be lower for Black pupils where they are relatively numerous, but that no such attenuation exists for pupils of South Asian origin. Indeed, for these groups, segregation is higher where they are relatively numerous. Finally, for Black pupils there are no LEAs where segregation is measured to be high along both dimensions, but there are a few such places for pupils of South Asian origins, and furthermore these are LEAs where that aggregate group is relatively numerous.

Comparing segregation in schools and in neighbourhoods, it is clear that while the two are related, the two do not map one-for-one, and the two indices are generally not equal. For most of the ethnic groups, the weight of data generally suggests that the school-based indices are slightly greater than the neighbourhood-based indices, though the differences are sometimes marginal. That is to say, children are more segregated in school than in their neighbourhood. This seems more clearly true of children with Black Caribbean heritage, children of Indian ethnicity, Pakistani ethnicity and Bangladeshi ethnicity, and less true of children with Black African heritage. Our regression analysis shows that the ratio of school to neighbourhood segregation increases with the population density of the area.

Subsequent work needs to provide interpretation for these results. All writers in this field acknowledge that 'segregation' results from a complex and multifaceted set of processes. Nevertheless, to make further progress in understanding these facts, some (different) behavioural models of the underlying processes are required. Also, we need a greater understanding of the consequences of segregation. Clotfelter's (2001, p.199) view, quoted above, is that segregation 'may affect such things as the level and distribution of academic achievement in the population, racial attitudes, subsequent social and economic outcomes of students, and patterns of residential integration'. We aim to pursue the first of these using the newly-available PLASC data. Thus while 
we have provided answers to the questions we raised in the Introduction, there is more work to do than work done. 


\section{References}

Amin, K., Drew, D., Fosam, B. and Gillborn, D., with Demack, S. (1997) Black and ethnic minority young people and educational disadvantage. London: Runnymede Trust.

Arrow, K.J. (1998) 'What has economics to say about racial discrimination?' Journal of Economic Perspectives, 12(2): 91-100.

Bayer, P., McMillan, R. and Rueben, K. (2003) 'What drives racial segregation? New evidence using census microdata', mimeo.

Bean, F.D. and Tienda, M. (1987) The Hispanic population of the United States. New York: Russell Sage Foundation.

Bhattacharyya, G., Ison, L. and Blair, M. (2003) Minority ethnic attainment and participation in education and training: the evidence, DfES Research Topic Paper RTP01-03. London: DfES.

Blalock, H.M. (1967) Toward a theory of minority-group relations. London: John Wiley \& Sons.

Borjas, G.J. (1997) To ghetto or not to ghetto: ethnicity and residential segregation. NBER Working Paper 6176. Cambridge, MA: NBER.

Burgess, S. and Wilson, D. (2003) Ethnic segregation in England's schools. CMPO Working Paper 03/086. Bristol: CMPO, University of Bristol.

Burgess, S., McConnell, B., Propper, C. AND Wilson, D. (2004) Sorting and choice in English secondary schools. CMPO Working Paper 04/111. Bristol: CMPO, University of Bristol.

Cantle, T. (2001) Community Cohesion: a Report of the Independent Review Team. London: Home Office. http://www.homeoffice.gov.uk/docs/community cohesion.pdf.

Case, A.C. and Katz, L.F. (1991) The company you keep: the effects of family and neighbourhood on disadvantaged youths. NBER Working Paper 3705. Cambridge, MA: NBER.

Cline, T., De Abreu, G., Fihosy, C., Gray, H., Lambert, H. and Neale, J. (2002) Minority ethnic pupils in mainly White schools, DfES Research Report RR365. London: DfES.

Clotfelter, C.T. (1998) Public school segregation in metropolitan areas. NBER Working Paper 6779. Cambridge, MA: NBER.

Clotfelter, C.T. (2001) 'Are Whites still fleeing? Racial patterns and enrolment shifts in urban public schools, 1987-1996', Journal of Policy Analysis and Management, 20(2): 199-221. 
Coleman, J., Campbell, E., Hobson, C.J., McPartland, J., Mood, A.M., Weinfeld, F.E. and York, R.L. (1966) Equality of Educational Opportunity. Washington DC: US Department of Health, Education and Welfare.

Crane, J. (1991) 'The epidemic theory of ghettos and neighbourhood effects on dropping out and teenage childbearing', American Journal of Sociology, 96: 1226-1259.

Cutler, D.M. and Glaeser, E.L. (1997) 'Are ghettos good or bad?' Quarterly Journal of Economics, 112: 827-872.

Cutler, D.M., Glaeser, E.L. and Vidgor, J.L. (1999) 'The rise and decline of the American ghetto', Journal of Political Economy, 107(3): 455-506.

Dorsett, R. (1998) Ethnic minorities in the inner city. Bristol: Policy Press.

Duncan, O.D. and Duncan, B. (1955) 'A methodological analysis of segregation indexes', American Sociological Review, 20: 210-217.

Frankenberg, E., Lee, C. and Orfield, G. (2003) A multiracial society with segregated schools: are we losing the dream? Cambridge MA: Civil Rights Project, Harvard University. http://www.civilrightsproject.harvard.edu .

Gillborn, D. and Mirza, H.S. (2000) Educational inequality: mapping race, class and gender. London: Ofsted.

Glennerster, H. (1991) 'Quasi-markets for education?' Economic Journal, 101: 1268-1276.

Gorard, S. (2000) Education and Social Justice. Cardiff: University of Wales Press.

Gorard, S. and Fitz, J. (1998a) 'The more things change ... the missing impact of marketisation?' British Journal of Sociology of Education, 19: 365376.

Gorard, S. and Fitz, J. (1998b) 'Under starters orders: the established market, the Cardiff study and the Smithfield project', International Studies in Sociology of Education, 8: 299-314.

Gorard, S., Taylor, C. and Fitz, J. (2003) Schools, Markets and Choice Policies. London: Routledge Falmer.

Haddock, M. (2003) Summary report on community cohesion initiatives in Oldham primary schools, http://www.oldham.gov.uk/learning /cohesion/oldham_schools_cohesion_report.pdf.

House of Commons (2004) Social Cohesion, London: The Stationary Office. 
Johnston, R.J. (1984) Residential Segregation, the State and Constitutional Conflict in American Urban Areas. London: Academic Press for the Institute of British Geographers, Special Publication 17.

Johnston, R., Wilson, D. and Burgess, S. (2004) 'School segregation in multiethnic England', Ethnicities, 4, 2: 237-265.

Massey, D.S. and Denton, N.A. (1988) 'The dimensions of residential segregation', Social Forces, 67: 281-315.

Massey, D.S. and Denton, N.A. (1989) 'Hypersegregation in United States metropolitan areas - Black and Hispanic segregation across five dimensions', Demography, 26: 373-391.

Massey, D.S. and Denton, N.A. (1993) American Apartheid: Segregation and the making of the underclass. Cambridge, MA: Harvard University Press.

McKinney, S. and Schnare, A.B. (1989) 'Trends in residential segregation by race: 1960-1980', Journal of Urban Economics, 26: 269-280.

Ouseley, H. (2001) Community pride not prejudice: making diversity work in Bradford. Bradford: Bradford Vision http://www.bradford2020.com/pride/report.pdf.

Peach, C. (1996) 'Does Britain have ghettos?' Transactions of the Institute of British Geographers, New Series, 21(1): 216-235.

Reardon, S.F., Yun, F.T. and McNulty, T. Eitle (2000) 'The changing structure of school segregation: measurement and evidence of multiracial metropolitan-area school segregation, 1989-1995', Demography, 37(3): 351-364.

Rivkin, S. (1994) 'Residential segregation and school integration', Sociology of Education, 67: 279-292.

Rivkin, S.G. (2000) 'School desegregation, academic attainment and earnings', Journal of Human Resources, 35(2): 333-346.

Schelling, T.C. (1971) 'Dynamic models of segregation', Journal of Mathematical Sociology, 1: 143-186.

Simpson, L. (2004) 'Statistics of racial segregation: measures, evidence and policy’, Urban Studies, 41(3): 661-681.

Tomlinson, S. (2001) 'Some success, could do better: education and race 19762000', in R. Phillips and J. Furlong (eds.) Education, Reform and the State: Twenty-five Years of Politics, Policy and Practice. London: Routledge.

Woodward, C Vann (2002) The strange career of Jim Crow. New York: Oxford University Press (First Edition: 1955). 